$1 \cdot r$

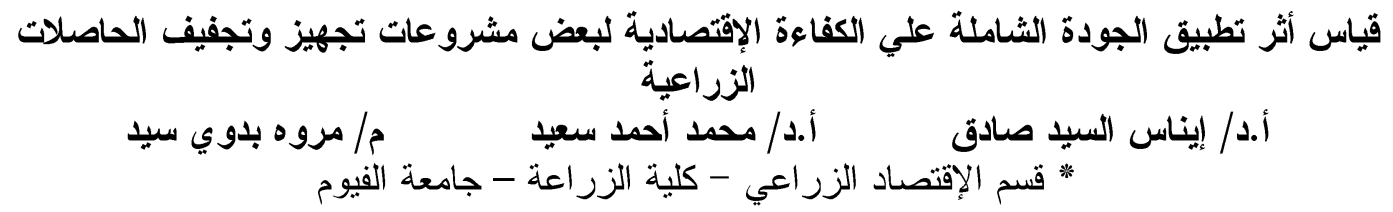

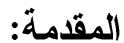

تعد الصناعة أحد الركائز الرئيسية لعملية التتمية الاقتصادية و الإجتماعية سواء كانت في الدول

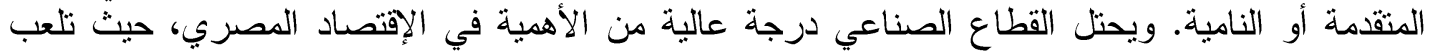

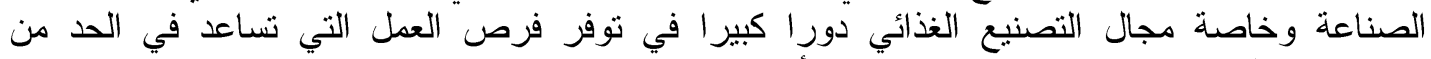

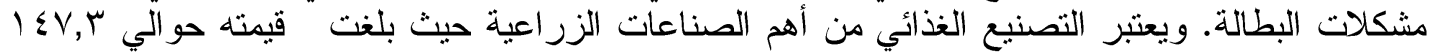

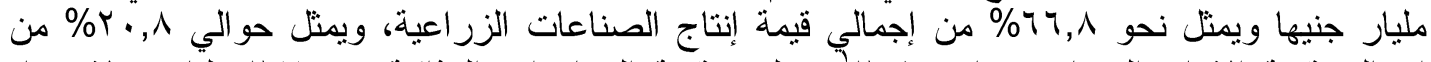

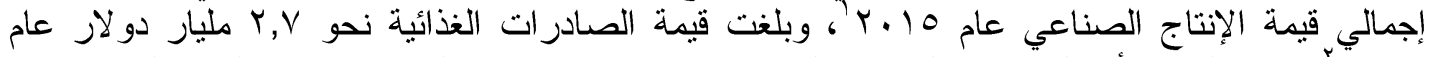

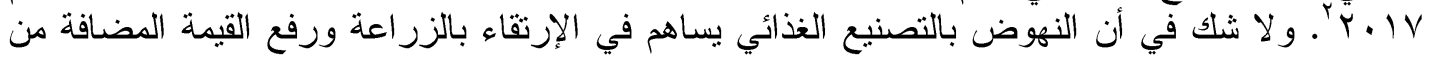

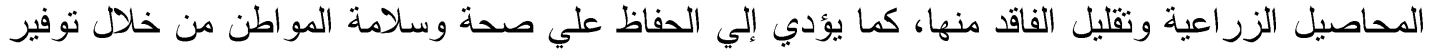

منتجات غذائية آمنة وصحية.

وجدير بالذكر أن عدد المشروعات الحاصلة علي شهادة الجودة (Iso 9000) يبلغ نحو 1 (Iso)

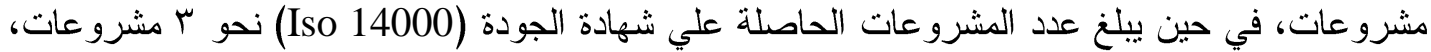

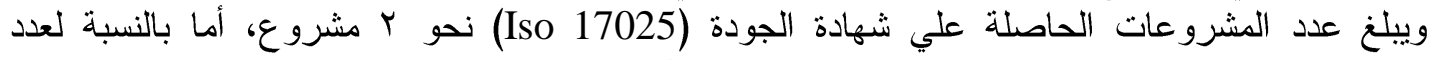

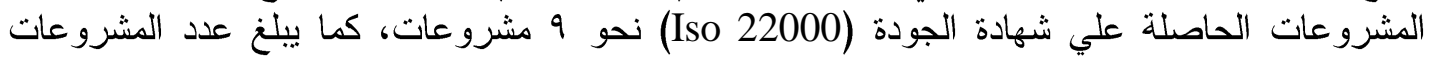

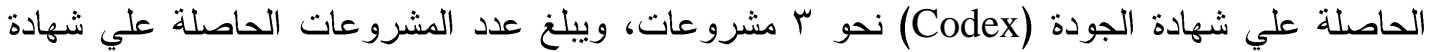

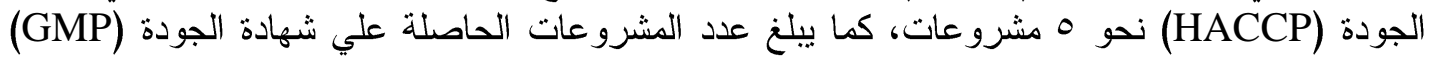
نحو 0 مشرو عات من إجمالي العينة. مشكلة الار استة:

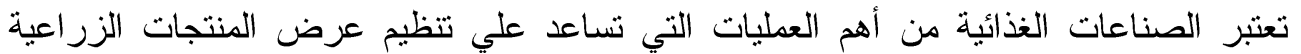

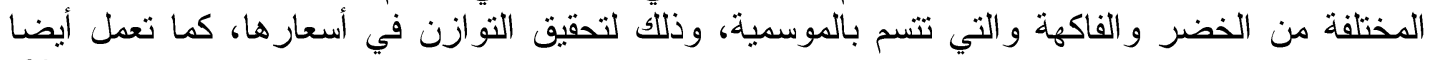

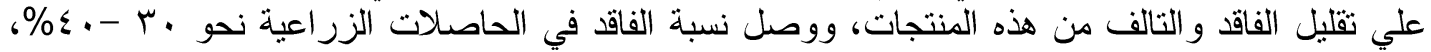

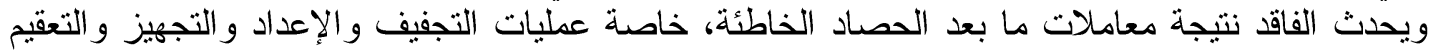

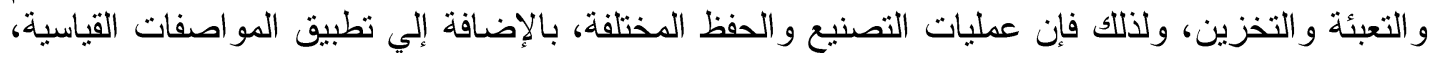

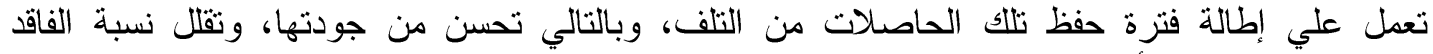
ومستويات التلوث، الأمر الذي يؤدى إلى زيادة الفرص التصديرية.

$$
\begin{aligned}
& \text { ' الجهاز المركزي للتعبئة العامة والإحصاء، النشرة السنوية لإحصاء الإتتاج الصناعي، } 17 \text { ــr. }
\end{aligned}
$$

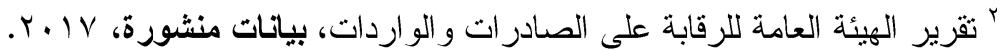

Fayoum J. Agric. Res. \& Dev., Vol. 33, No.1, January, 2019 
$1 \cdot \varepsilon$

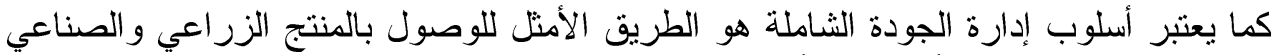

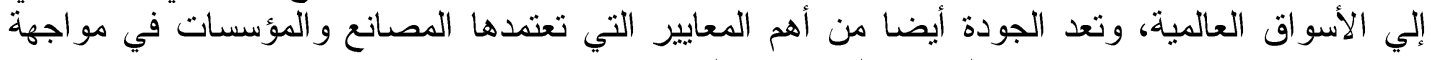
منافسيها ووفاء عملائها، وتحقيق الريادة علي هؤ لاء الثاء المنافسين.

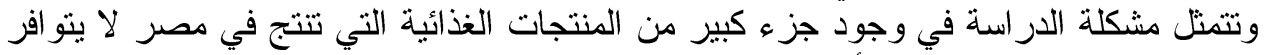

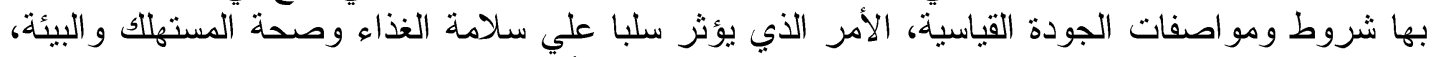

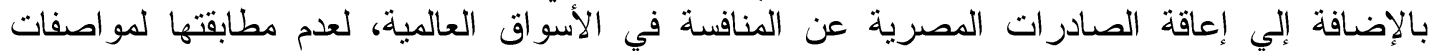
الجودة العالمية، مما أدي إلي خفض كمية الصادرات وخصوصاً من النباتات الطبية و العطرية.

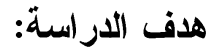

تستهدف هذه الدراسة قياس أثز إستخدام نظام الجودة الثاملة علي دعم الكفاءة الإقتصادية و القدرة التتافسية في الأسواق المحلية و العالمية، بإستخدام تحليل مغلف البيانات (DEA). الطريقة البحثية ومصادر البيانات:

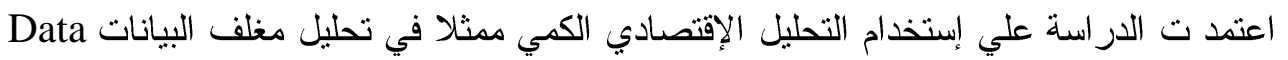
Envelopment Analysis (DEA)

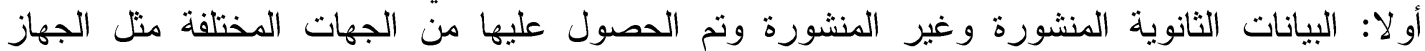

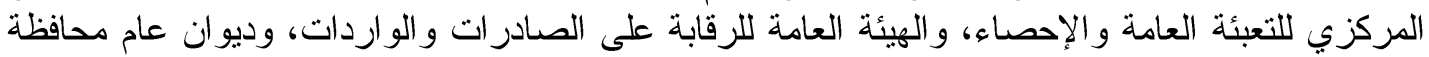

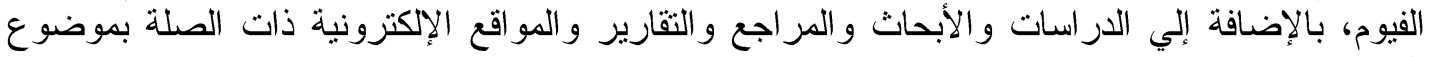

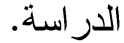
ثانيا: البيانات الأولية: و التي نم الحصول عليها من خلال المقابلة الثخصية للقائمين بإدارة بعض مشرو عات التهات

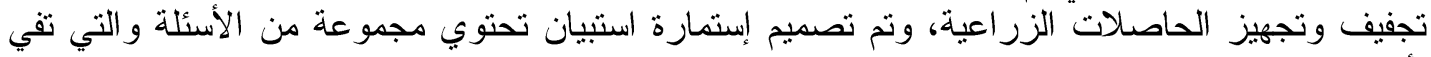
بأهداف الدر اسة. نتائج تحليل مغلف البيانات لبعض مشروعات تجهيز وتجفيف الحاصلات الزراعية: 1- - الكفاءة الإقتصادية (كفاعة الكلفة) لبعض مشروعات تجفيف النباتات الطبية و العطرية:

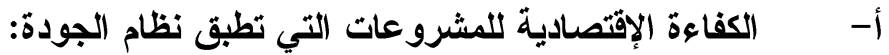

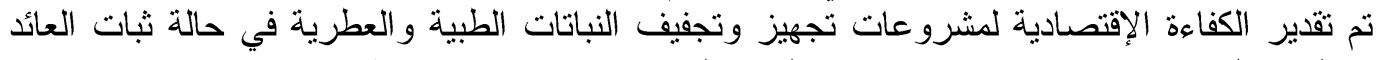

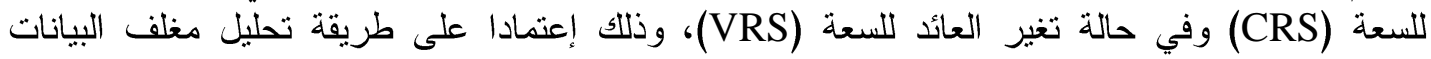
DEA بإستخدام برنامج DEAP علي الحاسب الآلي، وذلك لكل من تكاليف المادة الخام، و التكاليف

$$
\text { الأخري، وتكاليف الجودة. }
$$

- - - القدير الكفاءة الإقتصادية لتكاليف المادة الخام:

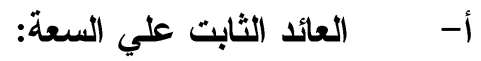

تشير بيانات الجدول رقم (1) إلي تقدير الكفاءة الإقتصادية في حالة ثبات العائد للسعة لتكاليف المادة

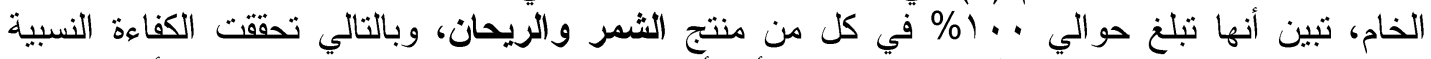

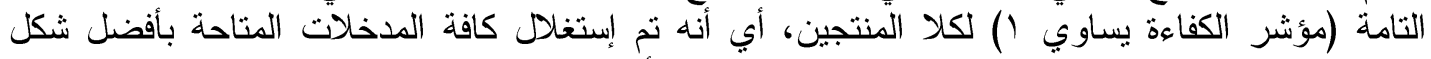

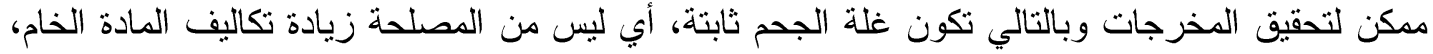

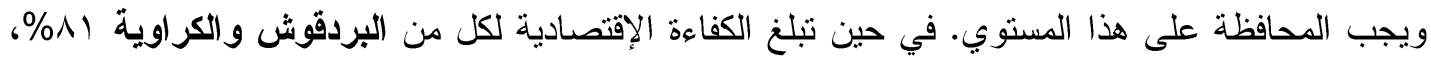

Fayoum J. Agric. Res. \& Dev., Vol. 33, No.1, January, 2019 
1.0

\% \% علي الترتيب، وتكون غلة الحجم متز ايدة، وبالتالي لم تتحقق الكفاءة التامة، وذلك لأن (مؤشر الكفاءة أقل من

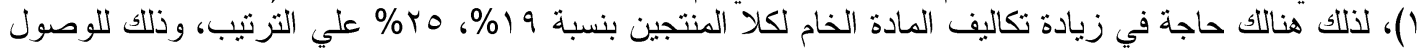

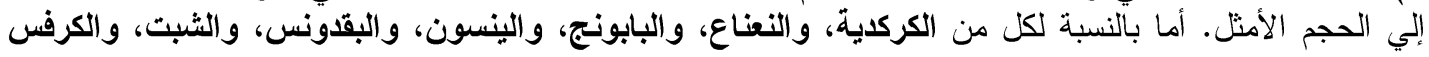

فتبلغ الكفاءة الإقتصادية. جدول (1): مؤشر كفاعة التكلفة حسب التوجيه الإدخالي لنموذجي CRS، VRS لتكاليف المادة الخام في

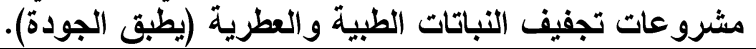

\begin{tabular}{|c|c|c|c|c|c|c|}
\hline \multirow[b]{2}{*}{ غلة الحجم } & \multicolumn{2}{|c|}{ نموذج عوائد الحجم المتغير } & \multicolumn{2}{|c|}{ نموذج عوائد الحجم الثابت } & \multirow{2}{*}{\multicolumn{2}{|c|}{$\begin{array}{c}\text { المنتج } \\
\text { (DMUs) }\end{array}$}} \\
\hline & مقدار عدم الكفاعة & 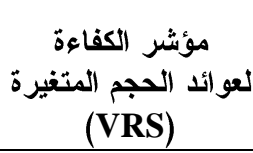 & مقدار عدم الكفاعة & 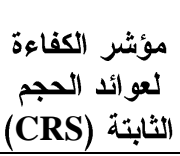 & & \\
\hline ثابتة & 0,0000 & 1,0000 & 0,0000 & 1.0000 & الثمر & 1 \\
\hline متتاقصة & 0,0000 & 1,0000 & 0,3243 & 0,6757 & الكركدية & r \\
\hline متتاقصة & 0,0401 & 0,9599 & 0,0991 & 0,9009 & النعناع & r \\
\hline ثابتة & 0,0000 & 1,0000 & 0,0000 & 1,0000 & الريحان & $\varepsilon$ \\
\hline منتاقصة & 0,0000 & 1,0000 & 0,0230 & 0,9770 & البابونج & 0 \\
\hline منز ايدة & 0,1667 & 0,8333 & 0,1892 & 0,8108 & البردقوش & 7 \\
\hline متز ايدة & 0,2308 & 0,7692 & 0,2516 & 0,7484 & الكر اوية & v \\
\hline مثتاقصة & 0,0000 & 1,0000 & 0,3666 & 0,6334 & الينسون & $\wedge$ \\
\hline متتاقصة & 0,1399 & 0,8601 & 0,1667 & 0,8333 & البقدونس & 9 \\
\hline متتاقصة & 0,0000 & 1,0000 & 0,1111 & 0,8889 & الثبت & 1. \\
\hline \multirow[t]{2}{*}{ متتاقصة } & 0,0000 & 1,0000 & 0,1558 & 0,8442 & الكرفس & 11 \\
\hline & \multicolumn{2}{|c|}{$11-1 \cdot-\lambda-0-\xi-1$} & \multicolumn{2}{|c|}{$\varepsilon-1$} & \multicolumn{2}{|c|}{ المنتجات المرجعية } \\
\hline
\end{tabular}

XLDEA المصدر : اعتمد على مخرجات برنة

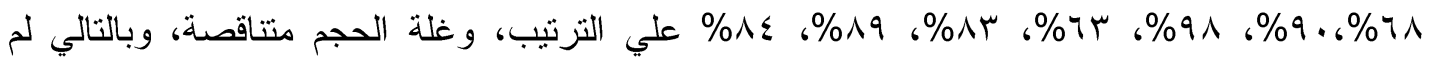

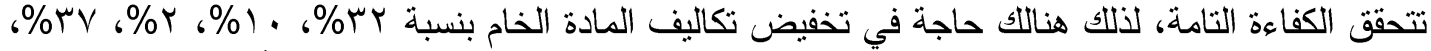

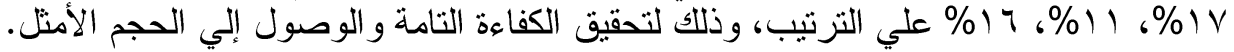

$$
\text { ب- - العائد المتغير علي السعة: }
$$

تثثير بيانات الجدول رقم (1) إلي تقدير الكفاءة الإقتصادية في حالة تغير العائد للسعة لتكاليف المادة

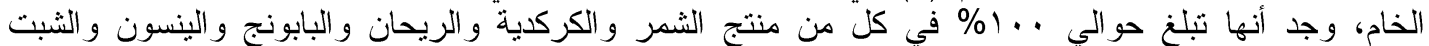

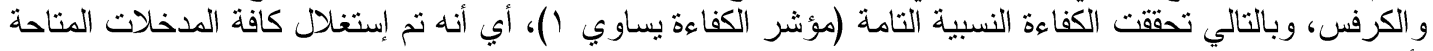

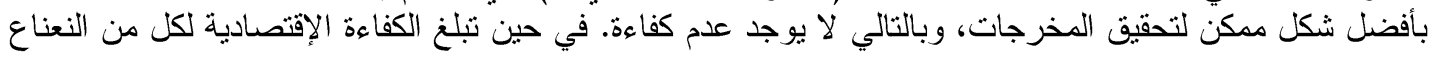

Fayoum J. Agric. Res. \& Dev., Vol. 33, No.1, January, 2019 
1.7

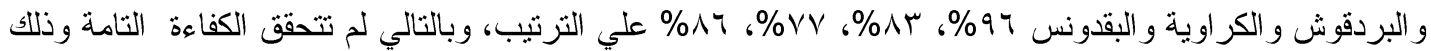

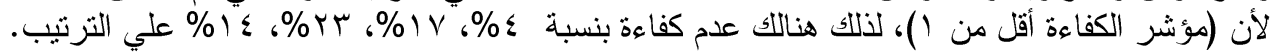

r

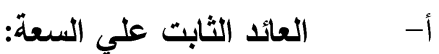

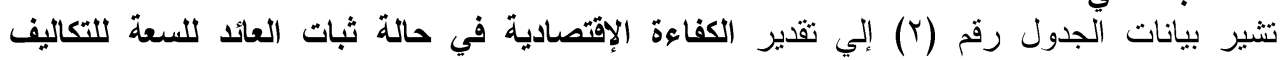

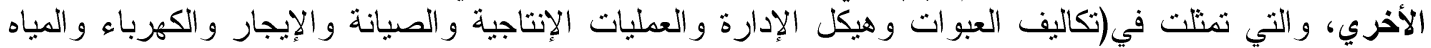

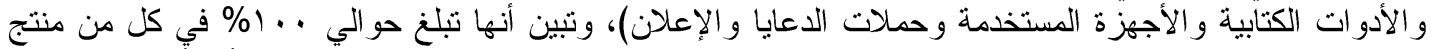

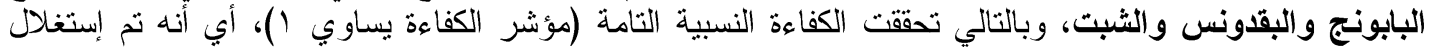

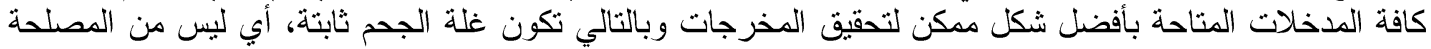

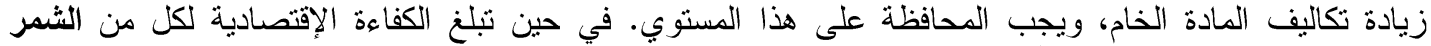

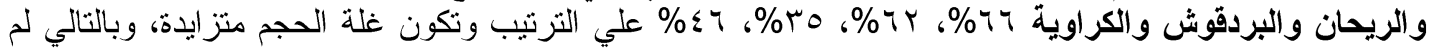

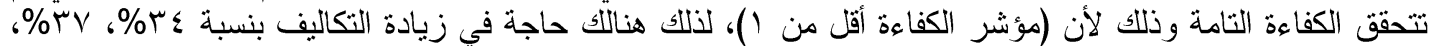

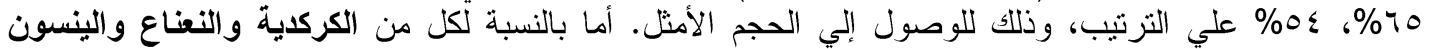

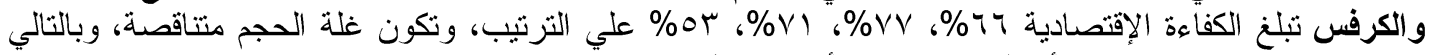

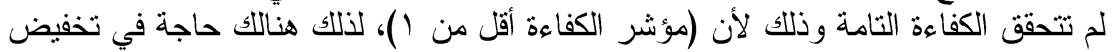

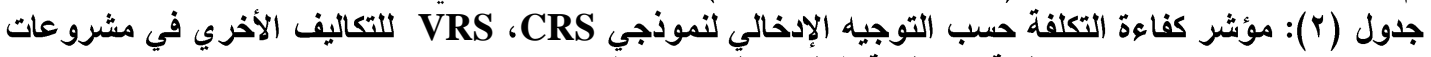

\begin{tabular}{|c|c|c|c|c|c|c|}
\hline \multirow{3}{*}{ غلة الحجم } & \multicolumn{2}{|c|}{ 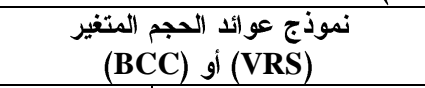 } & \multicolumn{2}{|c|}{ 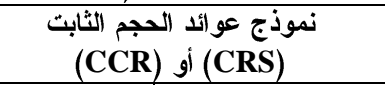 } & \multirow{2}{*}{\multicolumn{2}{|c|}{ (المنتج }} \\
\hline & \multirow{2}{*}{ مقار علدمة } & \multirow{2}{*}{$\begin{array}{c}\text { لعو أئد الحجم الكفاعة المتغيرة } \\
\text { (VRS) } \\
\text { (VRS } \\
0,9188\end{array}$} & \multirow{2}{*}{ مقدار عدم } & \multirow{2}{*}{$\begin{array}{c}\text { لعو ائد الحجر الكفاعة الثابتة } \\
\text { (ألثابة } \\
\text { (CRS) } \\
0,6582\end{array}$} & & \\
\hline & & & & & الثمر & 1 \\
\hline متتاقصة & 0,1793 & 0,8207 & 0,3400 & 0,6600 & الكركدية & r \\
\hline متتاقصة & 0,2341 & 0,7659 & 0,2431 & 0,7569 & النعناع & r \\
\hline متز ايدة & 0,3545 & 0,6455 & 0,3737 & 0,6263 & الريحان & $\varepsilon$ \\
\hline ثابتة & 0,0000 & 1,0000 & 0,0000 & 1,0000 & البابونج & 0 \\
\hline متز ايدة & 0,6143 & 0,3857 & 0,6462 & 0,3538 & البردقوش & $\uparrow$ \\
\hline متز يدة & 0,4990 & 0,5010 & 0,5404 & 0,4596 & الكر اوية & v \\
\hline منتاقصة & 0,0000 & 1,0000 & 0,2909 & 0,7091 & الينسون & $\wedge$ \\
\hline ثابتة & 0,0000 & 1,0000 & 0,0000 & 1,0000 & البقدونس & 9 \\
\hline ثابتة & 0,0000 & 1,0000 & 0,0000 & 1,0000 & الشبت & 1 . \\
\hline \multirow[t]{2}{*}{ متتاقصة } & 0,0000 & 1,0000 & 0,4716 & 0,5284 & الكرفس & 11 \\
\hline & \multicolumn{2}{|c|}{$11-1 \cdot-9-1-0$} & \multicolumn{2}{|c|}{$1 .-9-0$} & \multicolumn{2}{|c|}{ لمنتجات المرجعية } \\
\hline
\end{tabular}

XLDEA المصدر : اعتمد على مخرجات برنة

Fayoum J. Agric. Res. \& Dev., Vol. 33, No.1, January, 2019 
$1 \cdot V$

التكاليف الأخري تثير إلي (تكاليف الأجولة، الكرتون، المواد اللاصقة، أكياس البولي أثثلين، الخيط، تكاليف هيكل

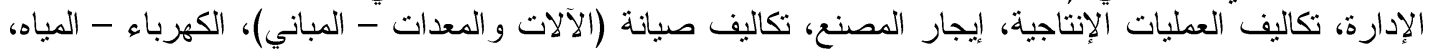
تكاليف حملات الدعايا و الإعلان، تكاليف الإنتاجية الأدوات الكتابية الكابية والأجهزة المستخدمة).

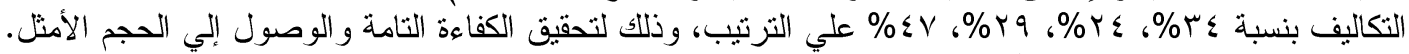

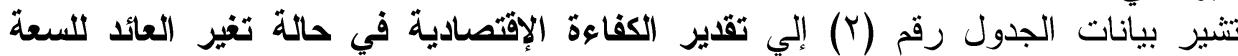
ب_ العائد المتغير علي السعة:

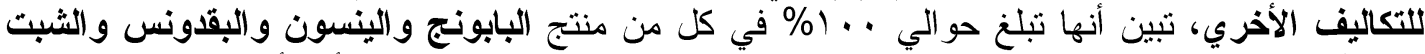

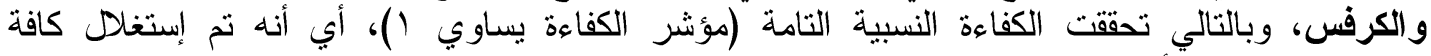

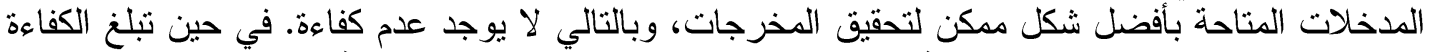

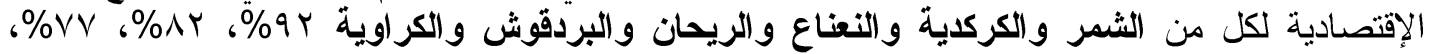

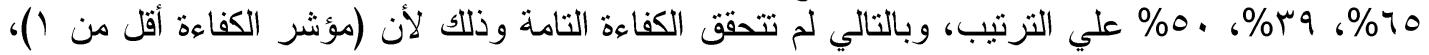

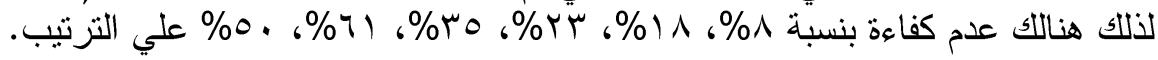

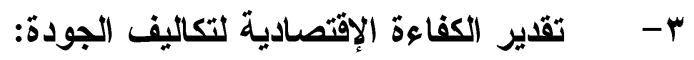

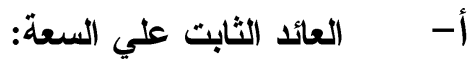

تشير بيانات الجدول رقم (r) إلي عند تقدير الكفائ الكفاءة الإقتصادية في حالة ثبات العائد

للسعة لتكاليف الجودة والتي تمثلت في تكاليف (المطابقة وعدم المطابقة وتكاليف الجودة الخفية)، تبين أنها

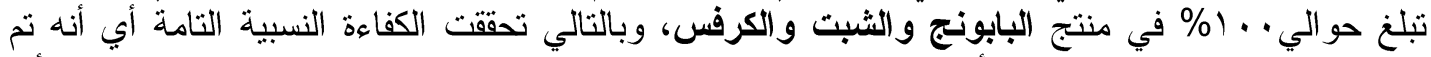

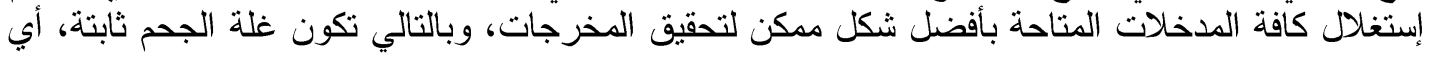

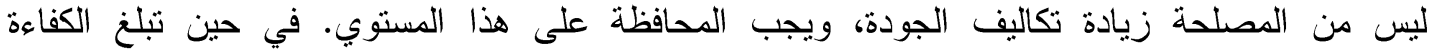

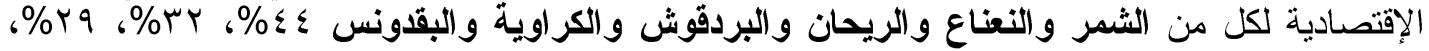

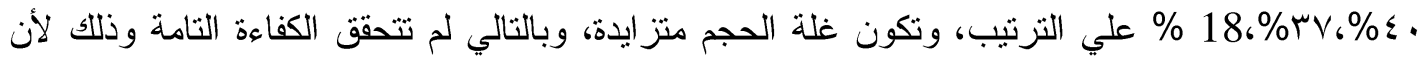

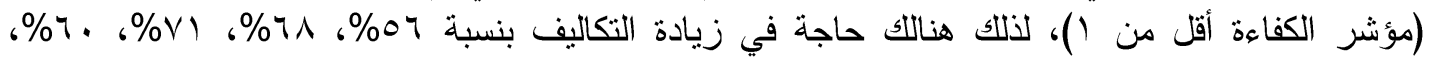

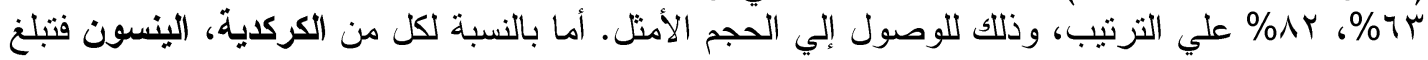

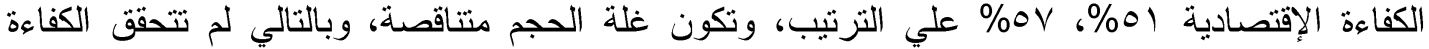

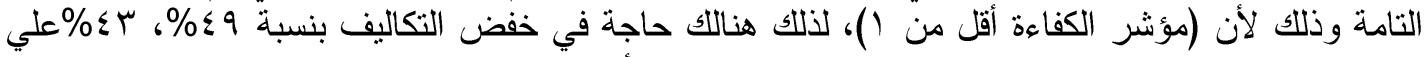

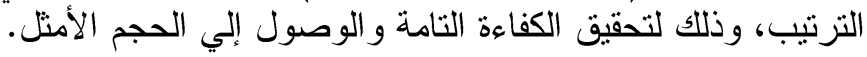

Fayoum J. Agric. Res. \& Dev., Vol. 33, No.1, January, 2019 
$1 \cdot 1$

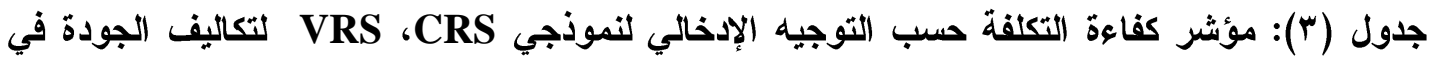
مشروعات تجفيف النباتات الطبية و العطرية (يطبق الجودة الجية).

\begin{tabular}{|c|c|c|c|c|c|c|}
\hline \multirow{3}{*}{ غلة الحجم } & \multicolumn{2}{|c|}{ نموذج عو ائد الحجم المتغير } & \multicolumn{2}{|c|}{ نموذج عوائد الحجم الثابت } & \multirow{2}{*}{\multicolumn{2}{|c|}{$\begin{array}{c}\text { المنتج) } \\
\text { (DMUs) }\end{array}$}} \\
\hline & \multirow{2}{*}{ مقدار علدم } & \multirow{2}{*}{$\begin{array}{c}\text { كو ائد الحجم الكفتغيرة } \\
\text { (VRS) } \\
\text { (VRS) } \\
0,5254\end{array}$} & \multirow{2}{*}{$\begin{array}{l}\text { مقدار عداء } \\
\text { الكفاءة } \\
0,5589\end{array}$} & \multirow{2}{*}{ 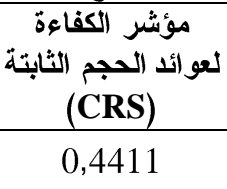 } & & \\
\hline & & & & & الثنمر & 1 \\
\hline متتاقصة & 0,3622 & 0,6378 & 0,4857 & 0,5143 & الكركدية & r \\
\hline متز ايدة & 0,6338 & 0,3662 & 0,6817 & 0,3183 & النعناع & $r$ \\
\hline 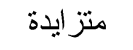 & 0,6523 & 0,3477 & 0,7055 & 0,2945 & الريحان & $\varepsilon$ \\
\hline ثابتة & 0,0000 & 1,0000 & 0,0000 & 1,0000 & البابونج & 0 \\
\hline 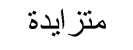 & 0,5202 & 0,4798 & 0,5977 & 0,4023 & البردقوش & 7 \\
\hline متز ايدة & 0,5640 & 0,4360 & 0,6344 & 0,3656 & الكر اوية & v \\
\hline متتاقصة & 0,0000 & 1,0000 & 0,4344 & 0,5656 & الينسون & $\wedge$ \\
\hline 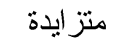 & 0,7834 & 0,2166 & 0,8198 & 0,1802 & البقدونس & 9 \\
\hline ثابتة & 0,0000 & 1,0000 & 0,0000 & 1,0000 & الثنبت & 1. \\
\hline \multirow[t]{2}{*}{ ثابتة } & 0,0000 & 1,0000 & 0,0000 & 1,0000 & الكرفس & 11 \\
\hline & \multicolumn{2}{|c|}{$11-1 \cdot-\lambda-0$} & \multicolumn{2}{|c|}{$11-1 \cdot-0$} & \multicolumn{2}{|c|}{ منتجات المرجعية } \\
\hline
\end{tabular}

تكاليف الجودة نثير إلي: تكاليف المطابقة (تقييم، وقاية)، تكاليف عدم المطابقة (الإخفاق الداخلي، الإخفاق الخارجي)، التكاليف الخفية للجودة.

ب- العائد المتغير علي السعة:

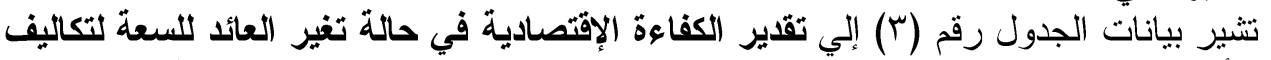

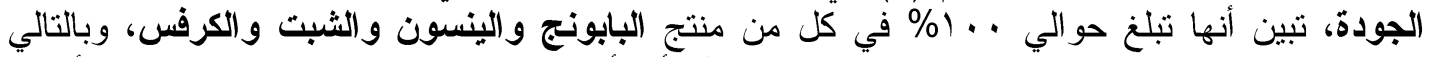

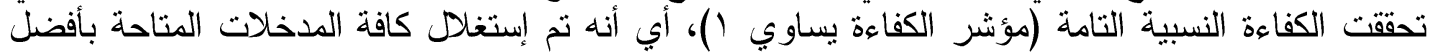

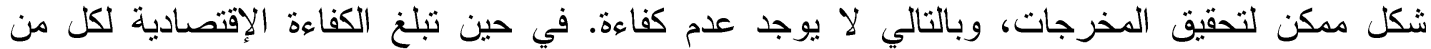

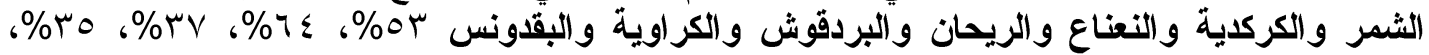

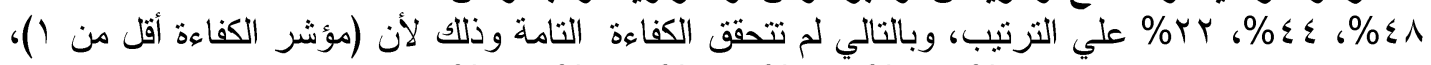

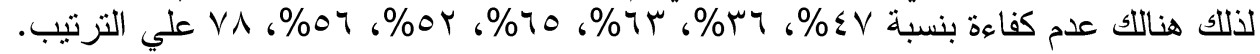

Fayoum J. Agric. Res. \& Dev., Vol. 33, No.1, January, 2019 
$1 \cdot 9$

ثانيا: الكفاءة الإقتصادية للمشروعات التي لا تطبق نظام إدارة الجودة: - إماير الكفاءة الإقتصادية لتكاليف المادة الخام:

أ- العائد الثابت علي السعة:

تشير بيانات الجدول رقم (ع) إلي تقدير الكفاءة الإقتصادية في حالة ثبات العائد للسعة لتكاليف

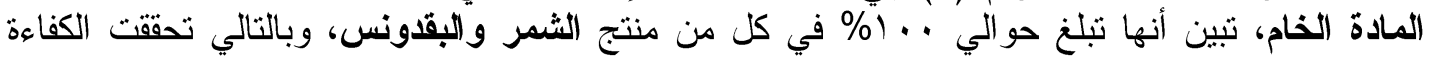

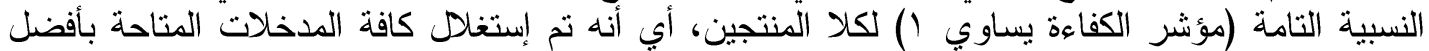
شكل ممكن لتحقيق المخرجات، وبالتالي تكون غلة الجحم ثابتة، أي ليس من المصلحة زيادة تكاليف المادة

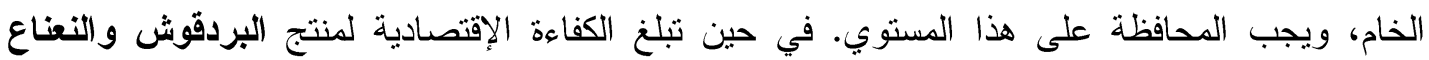

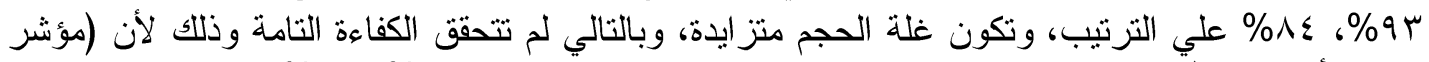

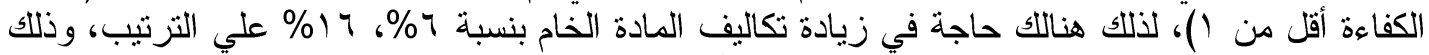

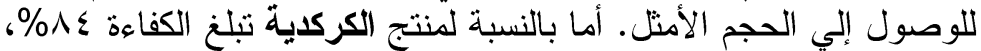

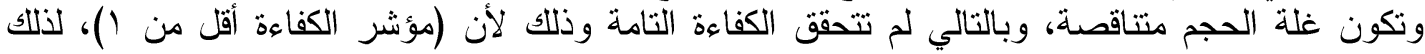
هنالك حاجة في تخفيض تكاليف المادة الخام بنسبة 7 (\%٪، وذلك لتحقيق الكفاءة التامة و الوصول إلى الكي الحجم

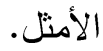

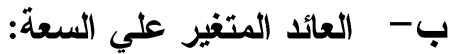

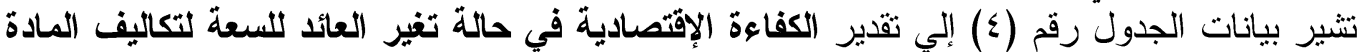

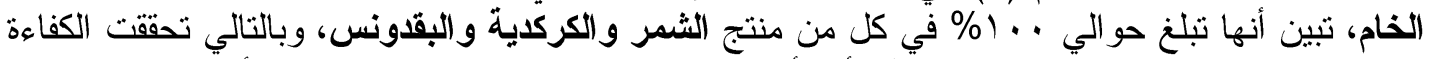
النسبية التامة (مؤشر الكفأَة يساوي (1)، أبي أنه تم إستخلال كافة المدخلات المتاحة بأفضل شكل فئل مكن

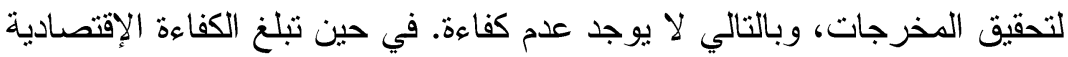

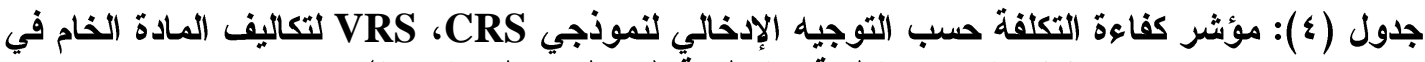

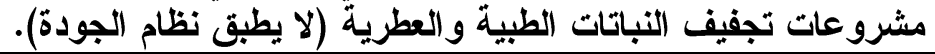

\begin{tabular}{|c|c|c|c|c|c|c|}
\hline \multirow{3}{*}{ غلة الحجم } & \multicolumn{2}{|c|}{ نموذج عو أئد الحجم المتغير } & \multicolumn{2}{|c|}{ نموذج عوائد الحجم الثابت } & \multirow{2}{*}{\multicolumn{2}{|c|}{$\begin{array}{c}\text { المنتج) } \\
\text { (DMUs) }\end{array}$}} \\
\hline & \multirow{2}{*}{ مقدار عدم } & \multirow{2}{*}{ 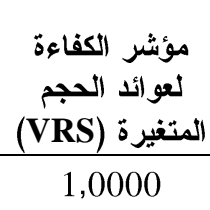 } & \multirow{2}{*}{ مقدار عدامة } & \multirow{2}{*}{$\begin{array}{c}\text { لعو ائد الحجر الكفاعة الثابتة } \\
\text { (CRS) } \\
\text { (CRS) } \\
1,0000\end{array}$} & & \\
\hline & & & & & الثمر & 1 \\
\hline متز ايدة & 0,0667 & 0,9333 & 0,0667 & 0,9333 & النعناع & $r$ \\
\hline متز ايدة & 0,0667 & 0,9333 & 0,1600 & 0,8400 & البردقوش & $r$ \\
\hline متتاقصة & 0,0000 & 1,0000 & 0,1582 & 0,8418 & الكركدية & $\varepsilon$ \\
\hline \multirow[t]{2}{*}{ ثابتة } & 0,0000 & 1,0000 & 0,0000 & 1,0000 & البقدونس & 0 \\
\hline & \multicolumn{2}{|c|}{$0-\xi-1$} & \multicolumn{2}{|r|}{$0-1$} & \multicolumn{2}{|c|}{ لمنتجات المرجعية } \\
\hline
\end{tabular}

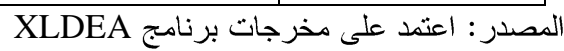

Fayoum J. Agric. Res. \& Dev., Vol. 33, No.1, January, 2019 
11.

لمنتج النعناع والبردقوش بو\% لكل منهما، وبالتالي لم تتحقق الكفاءة التامة، وذلك لأن (مؤشر الكفاءة أقل من ()، لذلك هنالك عدم كفاءة بنسبة V\% لكل منهما.

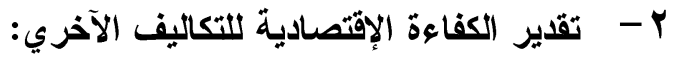

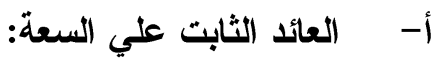

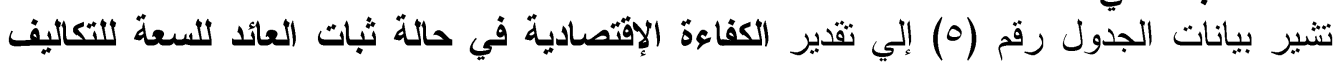
الأخري و التي تمثلت في (تكاليف العبوات و هيكل الإدارة و العمليات الإنتاجية و الصيانة و الإيجار و الكهرباء

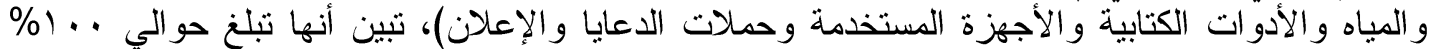

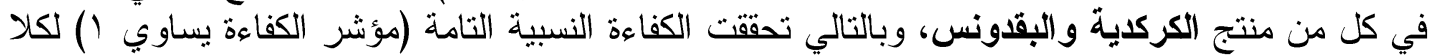

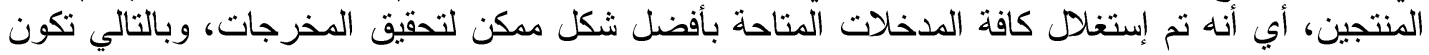

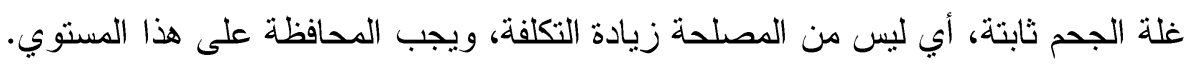

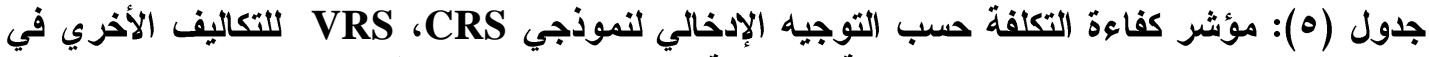

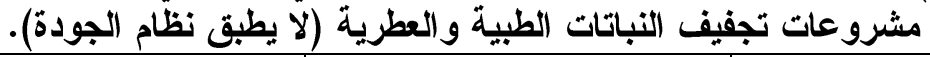

\begin{tabular}{|c|c|c|c|c|c|c|}
\hline \multirow[b]{2}{*}{ غلة الحجم } & \multicolumn{2}{|c|}{ نموذج عوائد الحجم المتغير } & \multicolumn{2}{|c|}{ نموذج عوائد الحجم الثابت } & \multirow{2}{*}{\multicolumn{2}{|c|}{$\begin{array}{c}\text { (DMUs) } \\
\text { (Dنتج) }\end{array}$}} \\
\hline & مقدار عدم & $\begin{array}{c}\text { لعو ائد الحجر الكفاءميرة } \\
\text { (VRS) }\end{array}$ & مقدار عدمة & 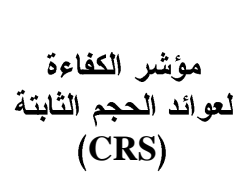 & & \\
\hline متز ايدة & 0,0042 & $\cdot, 99 \cdot \varepsilon$ & 0,2362 & ., vTru & الثمر & 1 \\
\hline منز ايدة & 0,2816 & 0,7184 & 0,2816 & 0,7184 & النعناع & r \\
\hline متز ايدة & 0,3824 & 0,6176 & 0,4442 & 0,5558 & البردقوش & $r$ \\
\hline ثابتة & 0,0000 & 1,0000 & 0,0000 & 1,0000 & الكركدية & $\varepsilon$ \\
\hline \multirow[t]{2}{*}{ ثابتة } & 0,0000 & 1,0000 & 0,0000 & 1,0000 & البقدونس & 0 \\
\hline & \multicolumn{2}{|r|}{$0-\xi$} & \multicolumn{2}{|r|}{$0-\xi$} & \multicolumn{2}{|c|}{ المنتجات المرجعية } \\
\hline
\end{tabular}

XLDEA المصدر : اعتمد على مخرجات برجنة

التكاليف الأخري تثير إلي (تكاليف الأجولة، الكرتون، المواد اللاصقة، أكياس البولي أثيلين، الخيط،

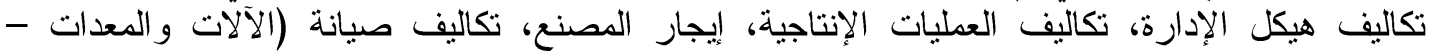
المباني)، الكهرباء - المياه، تكاليف حملات الدعايا و الإعلان، تكاليف الأدوات الكتابية والأجهزة (المستخدمة). (المباني)

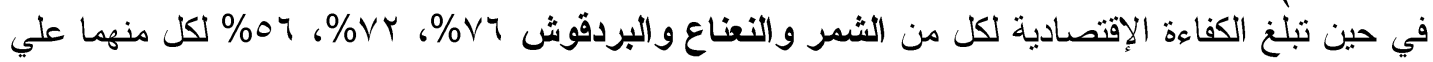

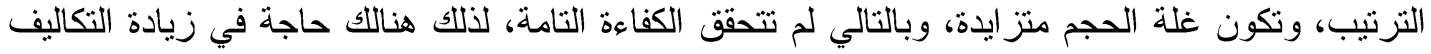

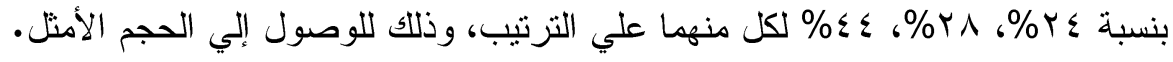

Fayoum J. Agric. Res. \& Dev., Vol. 33, No.1, January, 2019 
111

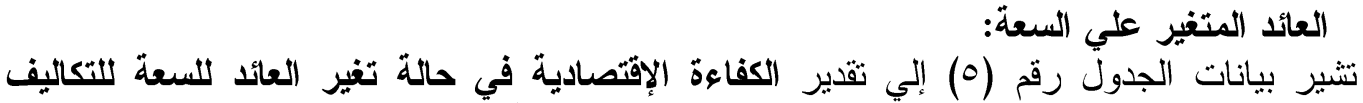

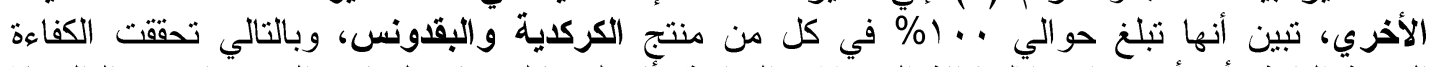

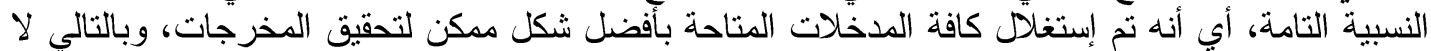

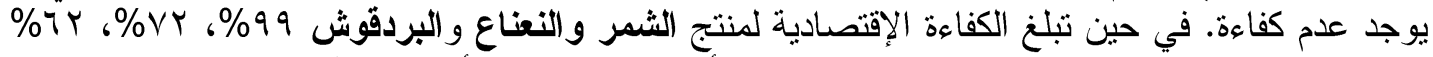

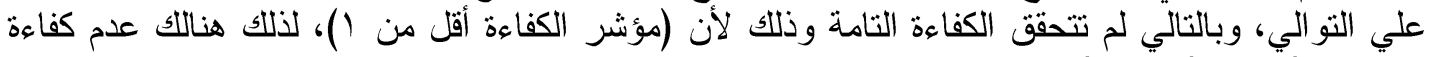

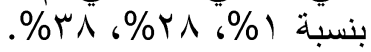

r - الكفاءة الإقتصادية (كفاءة الكلقة) لبعض مشروعات تجفيف محاصيل الخضر تطبق نظام الجودة:

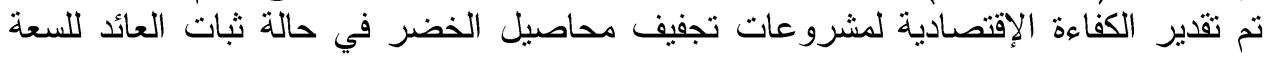

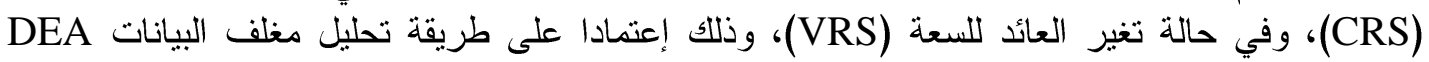

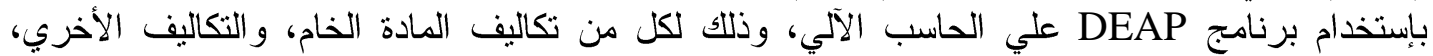
وتكاليف الجودة.

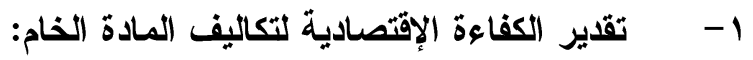

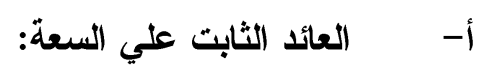

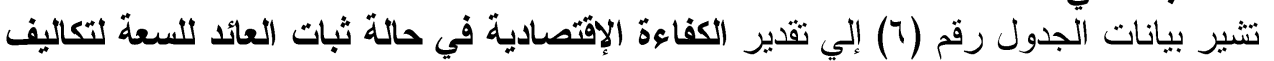

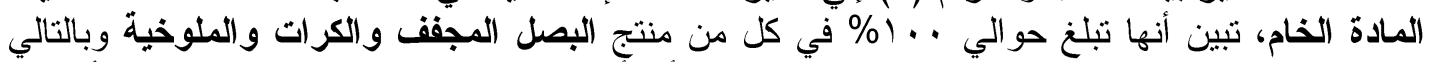

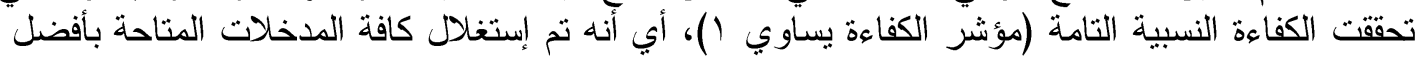

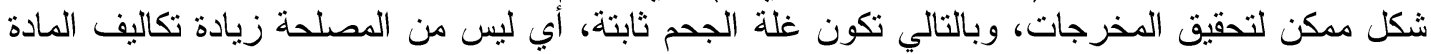

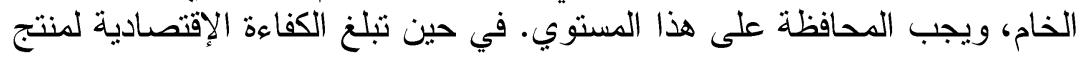
القاصوليا 8>\% وتكون غلة الحجم متزايدة، وبالتالي لم تتحقق الكفاءة التامة وذلك لأن (مؤشر الكفاءة أقل من ()، لذلك هناللك حاجة في زيادة تكاليف المادة الخام بنسبة 13\%، وذلك للوصول ولئ إلي الحجم الأمثل. أما

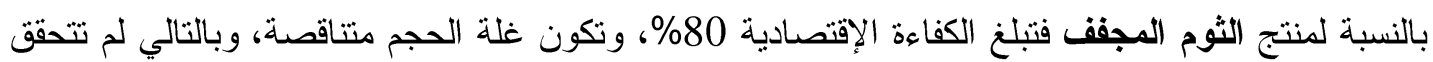

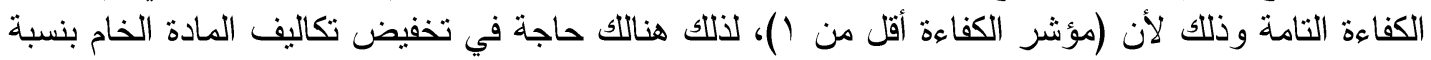
20\%، وذللك لتحقيق الكفاعة التامة و الوصول ودن إلي الحجم الأمثل. ب- العائد المتغير علي السعة: تشير بيانات الجدول رقم (ך) إلي تقدير الكفاءة الإقتصادية في حالة تغير العائد للسعة لتكاليف المادة

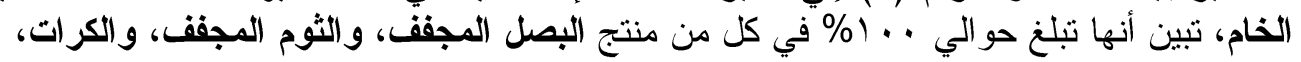

Fayoum J. Agric. Res. \& Dev., Vol. 33, No.1, January, 2019 
$11 \mathrm{r}$

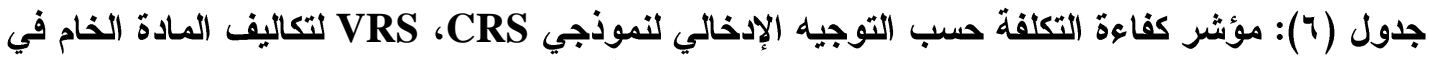

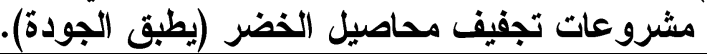

\begin{tabular}{|c|c|c|c|c|c|c|}
\hline \multirow[b]{2}{*}{ غلة الحجم } & \multicolumn{2}{|c|}{ نموذج عوائد الحجم المتغير } & \multicolumn{2}{|c|}{ نموذج عوائد الحجم الثابت } & \multirow{2}{*}{\multicolumn{2}{|c|}{$\begin{array}{c}\text { (DMUs) } \\
\text { (Dنتج) }\end{array}$}} \\
\hline & مقدار عدام & $\begin{array}{c}\text { لعو ائد الحجم الكفاعثيرة } \\
\text { (VRS) } \\
\text { (VRS) }\end{array}$ & مقار علام & 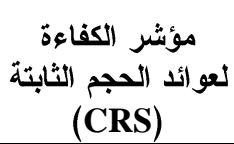 & & \\
\hline ثابتة & 0,0000 & 1,0000 & 0,0000 & 1,0000 & البصل مجفف & 1 \\
\hline متتاقصة & 0,0000 & 1,0000 & 0,1964 & 0,8036 & الثوم مجفف & r \\
\hline ثابتة & 0,0000 & 1,0000 & 0,0000 & 1,0000 & الكرات & r \\
\hline متز ايدة & 0,0000 & 1,0000 & 0,1250 & 0,8750 & الفاصوليا & $\leqslant$ \\
\hline \multirow[t]{2}{*}{ ثابتة } & 0,0000 & 1,0000 & 0,0000 & 1,0000 & الملوخية & 。 \\
\hline & & & \multicolumn{2}{|r|}{$0-r-1$} & \multicolumn{2}{|c|}{ لمنتجات المرجعية } \\
\hline
\end{tabular}

XLDEA المصدر : اعتمد على مخرجات برنية

و الفاصوليا، والملوخية، وبالتالي تحققت الكفاءة النسبية التامة (مؤشر الكفاءة يساوي ())، أب أنه تم إستخلال

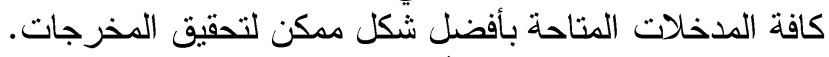

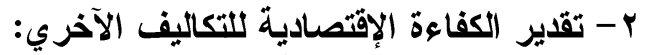

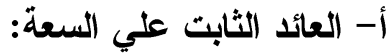

تشير بيانات الجدول رقم (V) إلي تقدير الكفاءة الإقتصادية في حالة ثبات العابت العائد للسعة للتكاليف

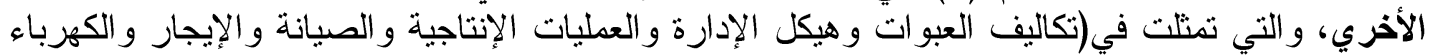

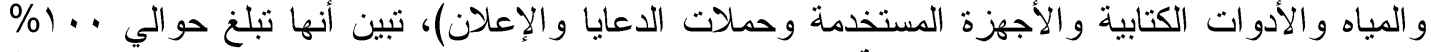

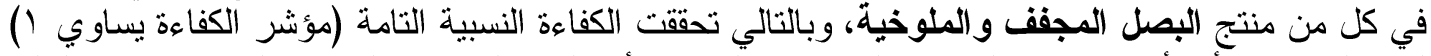

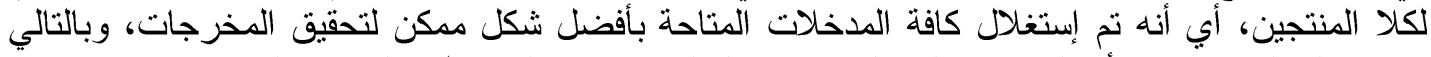
تكون غلة الجحم ثابتة، أي ليس من المصلحة زيادة التكلفة، ويجب المحافظة المخلة على هذا المستوي.

Fayoum J. Agric. Res. \& Dev., Vol. 33, No.1, January, 2019 
$11 \%$

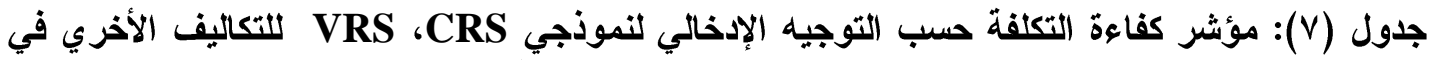
مشروعات تجفيف محاصيل الخضر (يطبق نظام الجودةً).

\begin{tabular}{|c|c|c|c|c|c|c|}
\hline \multirow[b]{2}{*}{ غلة الحجم } & \multicolumn{2}{|c|}{ نموذج عوائد الحجم المتغير } & \multicolumn{2}{|c|}{ نموذج عوائد الحجم الثابت } & \multirow{2}{*}{\multicolumn{2}{|c|}{$\begin{array}{c}\text { (المنتج) } \\
\text { (DMUs) }\end{array}$}} \\
\hline & مقدار عدام & $\begin{array}{c}\text { لعو ائد الحجم الكفائغيرة } \\
\text { (VRS) } \\
\text { (VRS) }\end{array}$ & مقدار عدام & $\begin{array}{c}\text { لعو ائش الحجر الكفاعة الثابتة } \\
\text { لعابتة } \\
\text { (CRS) }\end{array}$ & & \\
\hline ثابتة & 0,0000 & 1,0000 & 0,0000 & 1,0000 & البصل مجفف & 1 \\
\hline متتاقصة & 0,0000 & 1,0000 & 0,5971 & 0,4029 & الثوم مجفف & $r$ \\
\hline متز ايدة & 0,0000 & 1,0000 & 0,0663 & 0,9337 & الكرات & $r$ \\
\hline متز ايدة & 0,7993 & 0,2007 & 0,8439 & 0,1561 & الفاصوليا & 4 \\
\hline \multirow[t]{2}{*}{ ثابتة } & 0,0000 & 1,0000 & 0,0000 & 1,0000 & الملوخية & 5 \\
\hline & \multicolumn{2}{|r|}{$5-1$} & \multicolumn{2}{|r|}{$5-1$} & \multicolumn{2}{|c|}{ المنتجات المرجعية } \\
\hline
\end{tabular}

المصدر : اعتمد على مخرجات برنامج XLDEA

التكاليف الأخري تشير إلي (تكاليف الأجولة، الكرتون، المواد اللاصقة، أكياس البولي أثبلين، الخيط،

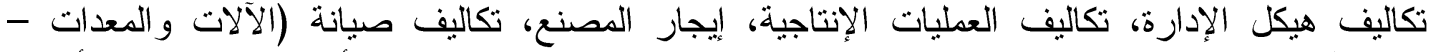

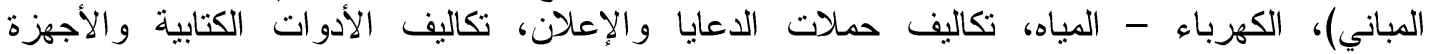

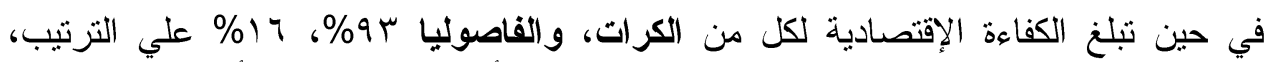
المستخدمة). (المباني.

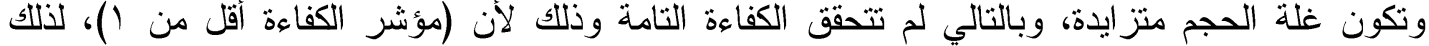

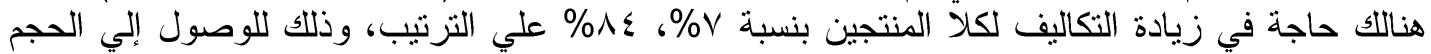

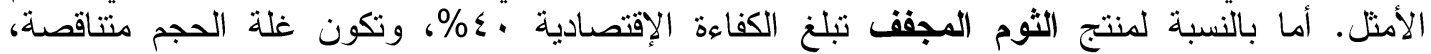

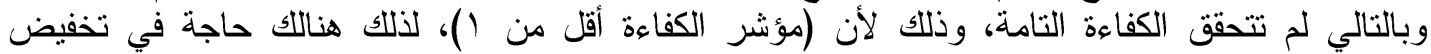

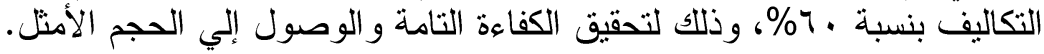

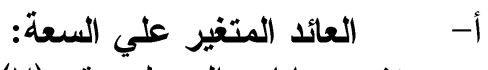

تشير بيانات الجدول رقم (V) إلي تقدير الكفاءة الإقتصادية في حالة تغير العائد للسعة للتكاليف

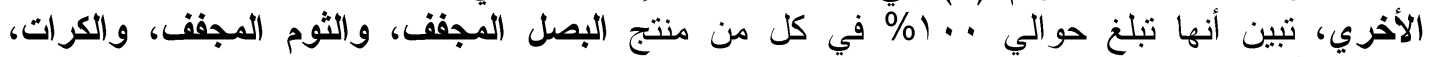

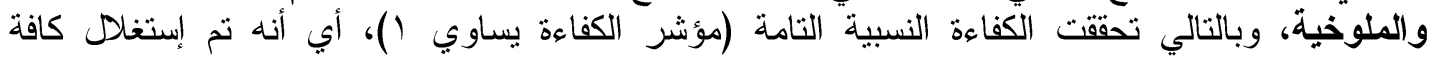

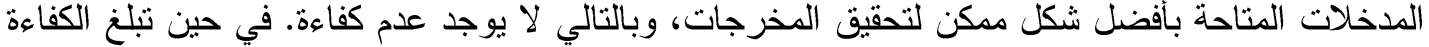

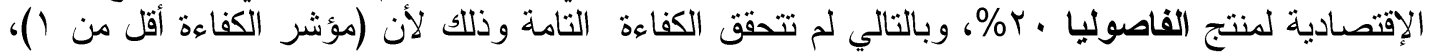

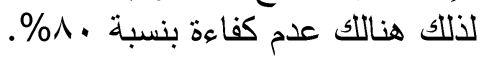

Fayoum J. Agric. Res. \& Dev., Vol. 33, No.1, January, 2019 
$11 \varepsilon$

\section{r- بقدير الكفاءة الإقتصادية لتكاليف الجودة:}

1- العائد الثابت علي السعة: الإقصادية

تشير بيانات الجدول رقم (^) إلي تقدير الكفاءة الإقتصادية في حالة ثبات العائد للسعة لتكاليف

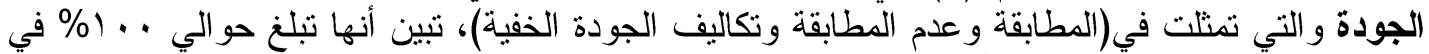

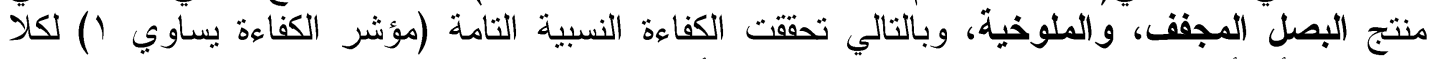

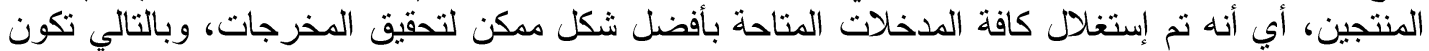

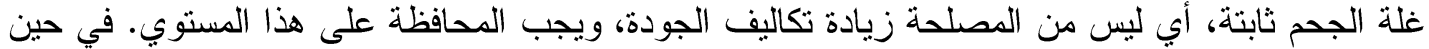

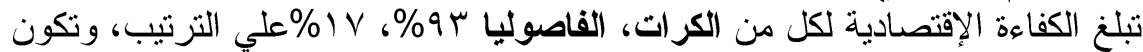

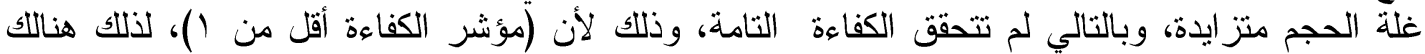

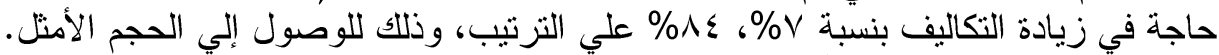
ب- العائد المتغير علي السعة:

تشير بيانات الجدول رقم (^) إلي تقدير الكفاءة الإقتصادية في حالة تغير العائد للسعة لتكاليف

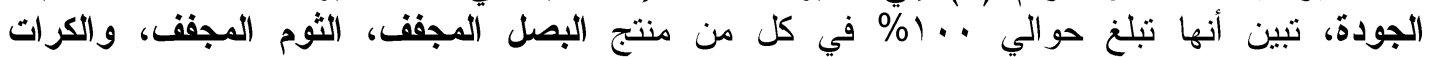

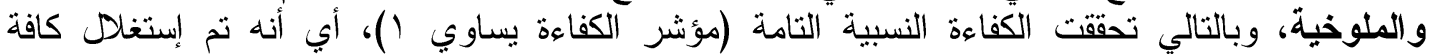

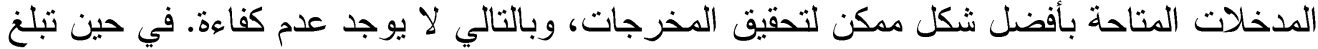

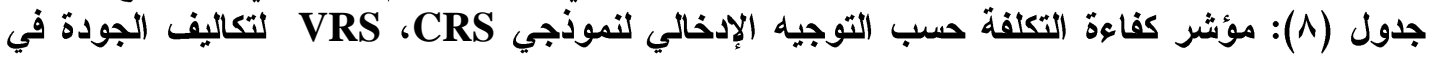
مشروعات تجفيف محاصيل الخضر (يطبق نظام الجودة الخدة).

\begin{tabular}{|c|c|c|c|c|c|c|}
\hline \multirow[b]{2}{*}{ غلة الحجم } & \multicolumn{2}{|c|}{ نموذج عوائد الحجم المتغير } & \multicolumn{2}{|c|}{ نموذج عوائد الحجم الثابت } & \multirow{2}{*}{\multicolumn{2}{|c|}{$\begin{array}{c}\text { المنتج) } \\
\text { (DMUs) }\end{array}$}} \\
\hline & مقدار عدام & $\begin{array}{c}\text { لعوائد الحجم الكفائرة } \\
\text { لمتيرة } \\
\text { (VRS) }\end{array}$ & مقدار علدم & $\begin{array}{c}\text { لعو ائد الحجر الكفاءة الثابتة } \\
\text { لعابثة } \\
\text { (CRS) }\end{array}$ & & \\
\hline ثابتة & 0,0000 & 1,0000 & 0,0000 & 1,0000 & البصل المجفف & 1 \\
\hline متتاقصة & 0,0000 & 1,0000 & 0,5971 & 0,4029 & الثوم المجفف & r \\
\hline متز ايدة & 0,0000 & 1,0000 & 0,0663 & 0,9337 & الكرات & $r$ \\
\hline متز ايدة & 0,79929 & 0,20071 & 0,8439 & 0,1561 & الفاصوليا & $\varepsilon$ \\
\hline \multirow[t]{2}{*}{ ثابتة } & 0,0000 & 1,0000 & 0,0000 & 1,0000 & الملوخية & 0 \\
\hline & & $0-\varepsilon-Y$ & & $0-1$ & بات المرجعية & 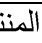 \\
\hline
\end{tabular}

المصدر : اعتمد على مخرجات برنامج XLDEA

تكاليف الجودة تثير إلي: تكاليف المطابقة (تقييم، وقاية)، تكاليف عدم المطابقة (الإخفاق الداخلي، الإخفاق

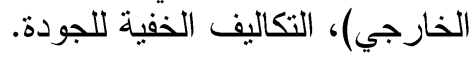

الكفاءة ألإقتصادية لمنتج الفاصوليا ـ r\%٪، وبالتالي لم تتحقق الكفاءة التامة، وذلك لأن (مؤشر الكفاءة أقل

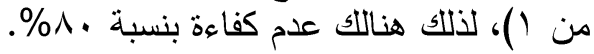

Fayoum J. Agric. Res. \& Dev., Vol. 33, No.1, January, 2019 
110

ثانيا: مقارنة المشروعات التي تطبق والتي لا تطبق نظام إدارة الجودة بإستخدام تحليل مظف البيانات (DEA)

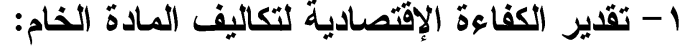

أ- ألعائد الثابت علي السعة:

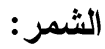

تشير بيانات الجدول رقم (9) إلي تقدير الكفاءة الإقتصادية في حالة ثبات العائد للسعة لتكاليف

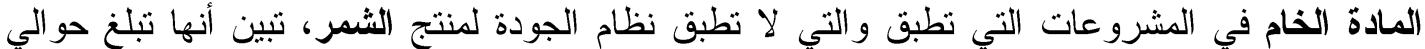

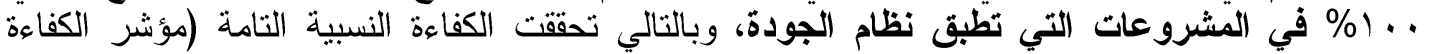

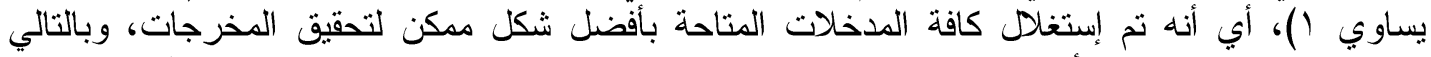

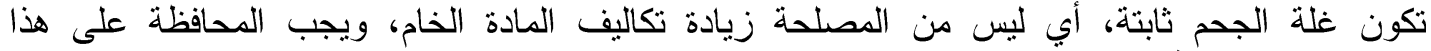

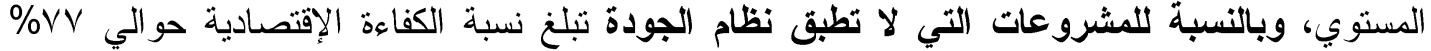

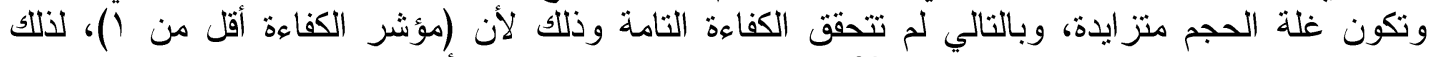

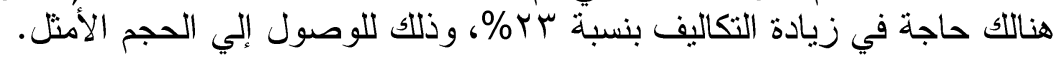
النعناع:

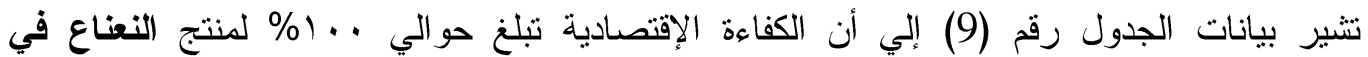

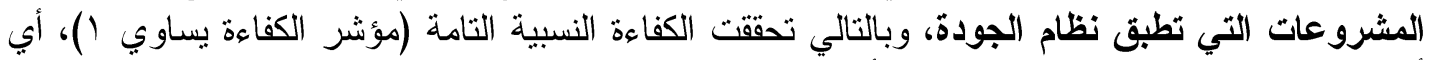

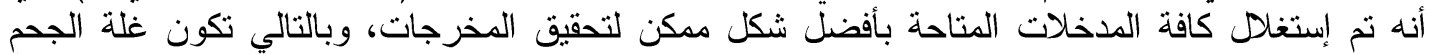

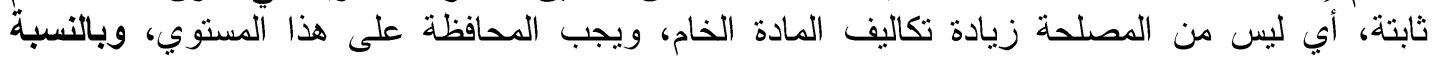

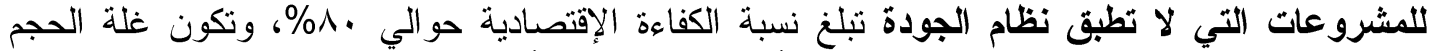

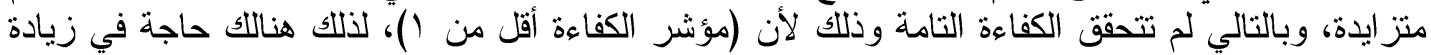

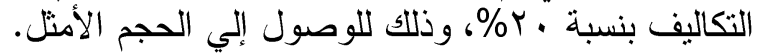

Fayoum J. Agric. Res. \& Dev., Vol. 33, No.1, January, 2019 
117

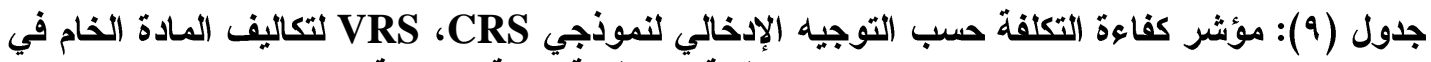

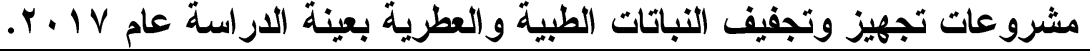

\begin{tabular}{|c|c|c|c|c|c|c|c|}
\hline \multirow{3}{*}{ ثلابتة } & \multicolumn{2}{|c|}{ نموذج عوائد الحجم المتغير } & \multicolumn{2}{|c|}{ نموذج عوائد الحجم الثابت } & \multirow{2}{*}{\multicolumn{3}{|c|}{$\begin{array}{c}\text { (المنتج) } \\
\text { (DMUs) }\end{array}$}} \\
\hline & \multirow{2}{*}{ مقدار عدم الكفاعة } & \multirow{2}{*}{ 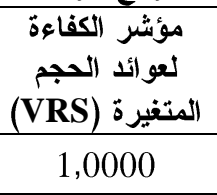 } & \multirow{2}{*}{\begin{tabular}{|l|l|} 
مقدار عدامة \\
0,0000
\end{tabular}} & \multirow{2}{*}{$\begin{array}{c}\text { لعوائد الحوبر الكفاءة الثابتة } \\
\text { لعابة } \\
\text { (CRS) } \\
1,0000\end{array}$} & & & \\
\hline & & & & & يطبق الجودة & \multirow{2}{*}{ الثمر } & \multirow{2}{*}{1} \\
\hline مثز ايدة & 0,2143 & 0,7857 & 0,2286 & 0,7714 & لا يطبق الجودة & & \\
\hline ثابتة & 0,0000 & 1,0000 & 0,0000 & 1,0000 & 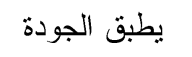 & \multirow{2}{*}{ النعناع } & \multirow{2}{*}{$r$} \\
\hline 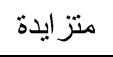 & 0,2000 & 0,8000 & 0,2000 & 0,8000 & لا يطبق الجودة & & \\
\hline مثز ايدة & 0,0714 & 0,9286 & 0,1000 & 0,9000 & يطبق الجودة & \multirow{2}{*}{ البردقوش } & \multirow{2}{*}{$r$} \\
\hline 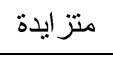 & 0,2667 & 0,7333 & 0,2800 & 0,7200 & لا يطبق الجودة & & \\
\hline متتاقصة & 0,0000 & 1,0000 & 0,2500 & 0,7500 & يطبق الجودة & \multirow{2}{*}{ | الكركدية } & \multirow{2}{*}{$\varepsilon$} \\
\hline متتاقصة & 0,1350 & 0,8650 & 0,3494 & 0,6506 & لا يطبق الجودة & & \\
\hline متتاقصة & 0,0000 & 1,0000 & 0,0435 & 0,9565 & يطبق الجودة & \multirow{2}{*}{ |البقدونس } & \multirow{2}{*}{0} \\
\hline متز ايدة & 0,1429 & 0,8571 & 0,1429 & 0,8571 & لا يطبق الجودة & & \\
\hline
\end{tabular}

المصدر : اعتمد على مخرجات برنامج لألجود

البردقوش:

يتبين من الجدول رقم (9) أن غلة الحجم لمنتج البردقوش متز ايدة في كلا المشرو عين وتبلغ نسبة الكفاءة

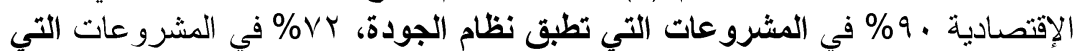

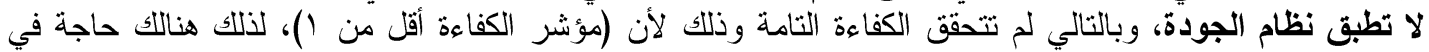

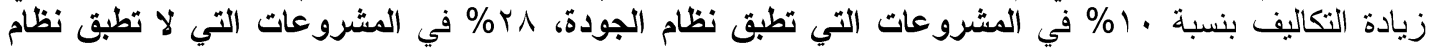
الجودة، وذلك للوصول إلي الحجم الأمثل. الكركدية

يتضح من الجدول رقم (9) أن غلة الحجم منتاقصة لمنتج الكركدية في كلا المشروعين، وبلغت نسبة

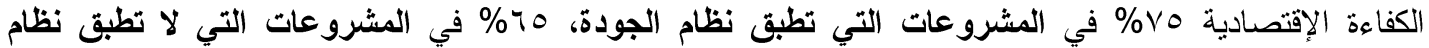

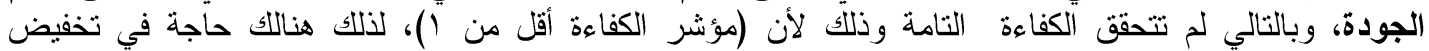

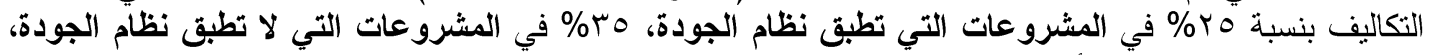
وذللك للوصول إلي الحجم الأمثل. البقدونس:

تشير بيانات الجدول رقم (9) إلي تقدير الكفاءة الإقتصادية في حالة ثبات العائد للسعة لتكاليف المادة

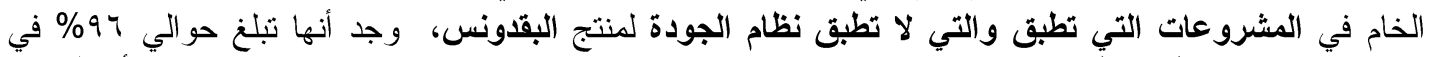

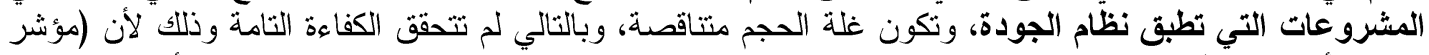

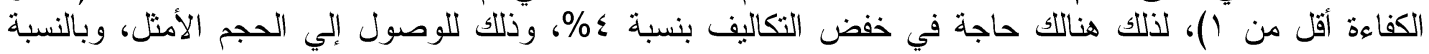

Fayoum J. Agric. Res. \& Dev., Vol. 33, No.1, January, 2019 
$11 \mathrm{~V}$

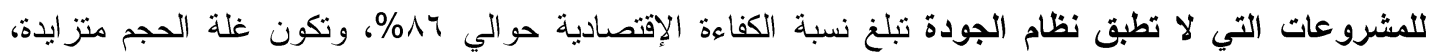

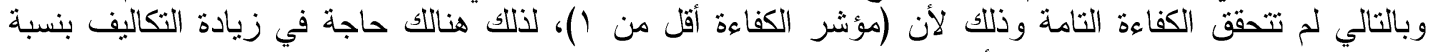

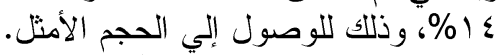

ب- العائد المتغير علي التسعة: الثمر:

تشير بيانات الجدول رقم (9) إلي تقدير الكفاءة الإقتصادية في حالة تغير العائد للسعة لتكاليف المادة الخام،

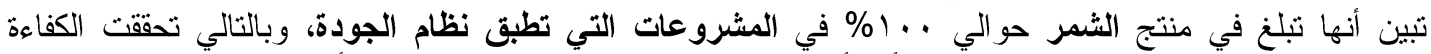

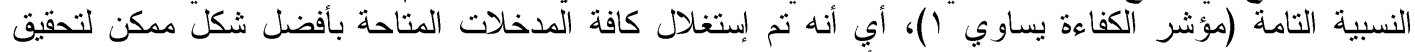

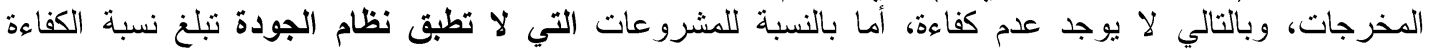

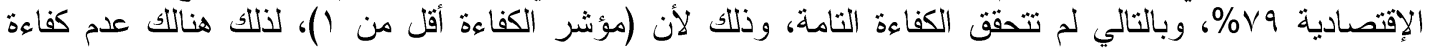

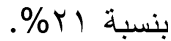
النعناع:

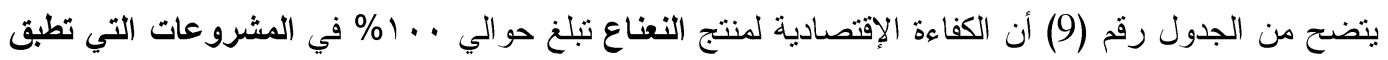

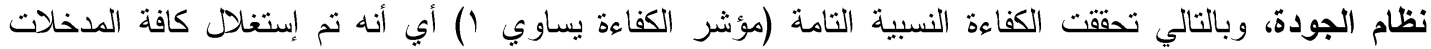

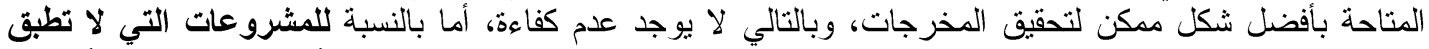

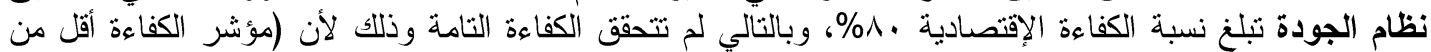

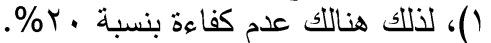

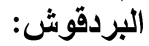

يتضح من الجدول رقم (9) أن الكفاءة الإقتصادية لمنتج البردقوش في المشروعات التي تطبق والتي لا تطبق

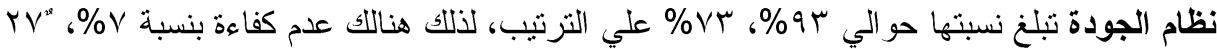
الكركدية: - الكودة

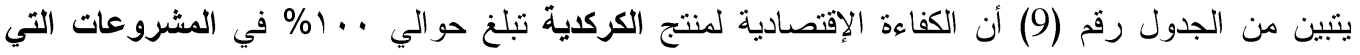

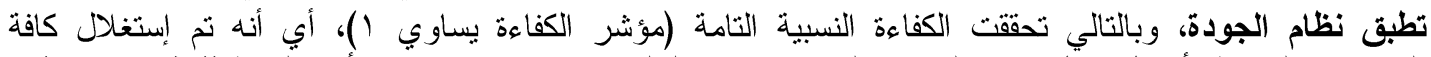

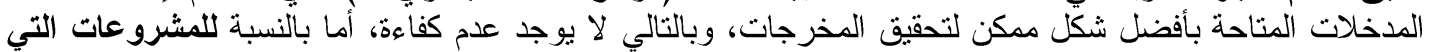

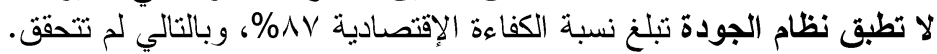
البقدونس: الانطئ نطام

تشير بيانات الجدول رقم (9) أن الكفاءة الإقتصادية لمنتج البقدونس تبلغ حوالي . . 1\% في المشروعات التي

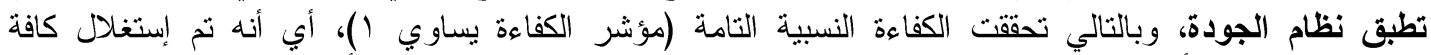

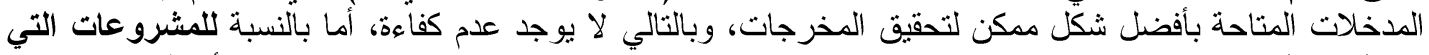

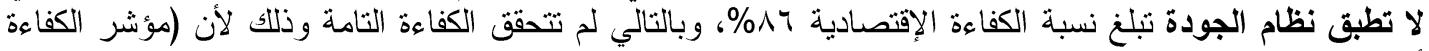

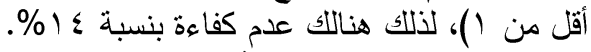
r - أقدير الكفاءة الإقتصادية للتكاليف الآخري:

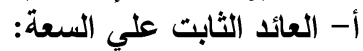
الثمر:

تشير بيانات الجدول رقم (10) إلي تقدير الكفاءة الإقتصادية في حالة تغير العائد للسعة للتكاليف الأخري

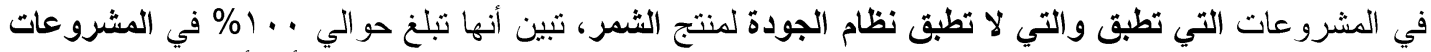

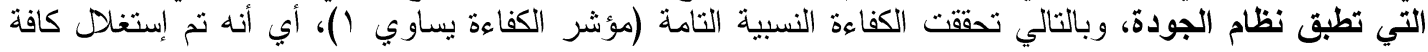

Fayoum J. Agric. Res. \& Dev., Vol. 33, No.1, January, 2019 
111

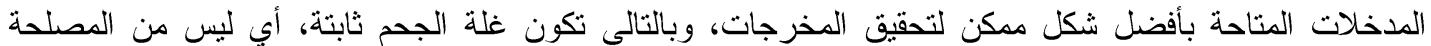

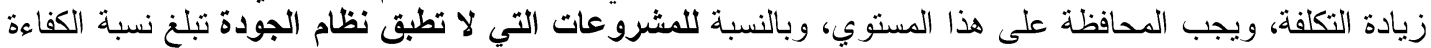

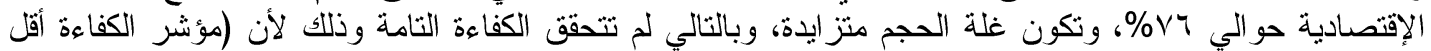

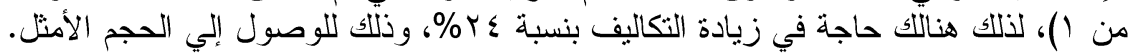
النعناع: (1)

يتضح من بيانات الجدول رقم (10) أن غلة الحجم لمنتج النعناع متز ايدة في كلا المشرو عين وتبلغ نسبة الكفاءة

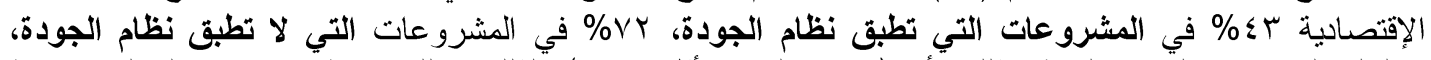

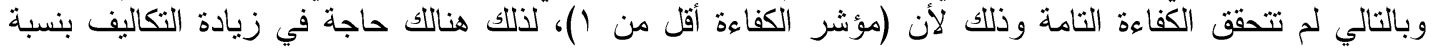

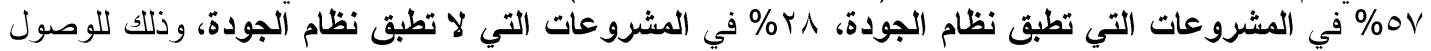

يتبين من بيانات الجدول رقم (10) أن غلة الحجم لمنتج البردقوش متز ايدة في كلا المشروعين، وتبلغ نسبة

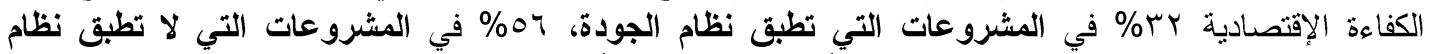

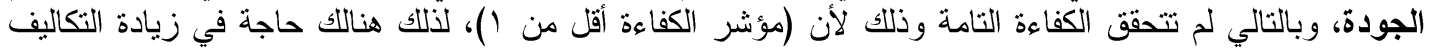

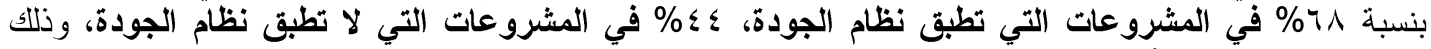

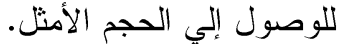

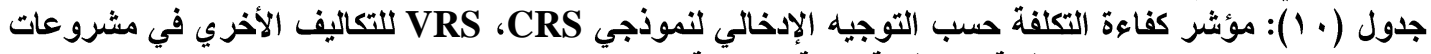

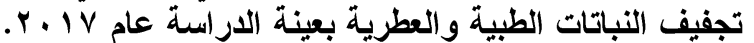

\begin{tabular}{|c|c|c|c|c|c|c|c|}
\hline \multirow[b]{2}{*}{ غلة الحجم } & \multicolumn{2}{|c|}{ نموذج عوائد الحجم المتغير } & \multicolumn{2}{|c|}{ نموذج عوائد الحجم الثابت } & \multirow{2}{*}{\multicolumn{3}{|c|}{$\begin{array}{c}\text { (DMUs) } \\
\text { (Dنتج) }\end{array}$}} \\
\hline & مقدار عدام & 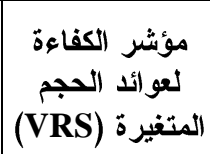 & مقدار عدام & لثوأشر الكفاءة الثابتة (CRS) & & & \\
\hline ثابتة & 0,0000 & 1,0000 & 0,0000 & 1,0000 & يطبق الجودة & \multirow{2}{*}{ 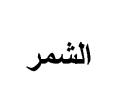 } & \multirow{2}{*}{1} \\
\hline متز ايدة & 0,0096 & 0,9904 & 0,2362 & 0,7638 & لا يطبق الجودة & & \\
\hline متز ايدة & 0,4978 & 0,5022 & 0,5721 & 0,4279 & يطبق الجودة & \multirow{2}{*}{ النعناع } & \multirow{2}{*}{ r } \\
\hline متز ايدة & 0,2816 & 0,7184 & 0,2816 & 0,7184 & لا يطبق الجودة & & \\
\hline متز ايدة & 0,6061 & 0,3938 & 0,6848 & 0,3152 & يطبق الجودة & \multirow{2}{*}{ البردقوش } & \multirow{2}{*}{ r } \\
\hline متز ايدة & 0,3824 & 0,6176 & 0,4442 & 0,5558 & لا يطبق الجودة & & \\
\hline متتاقصة & 0,0000 & 1,0000 & 0,5001 & 0,4999 & يطبق الجودة & \multirow{2}{*}{ الكركدية } & \multirow{2}{*}{$\varepsilon$} \\
\hline ثابتة & 0,0000 & 1,0000 & 0,0000 & 1,0000 & لا يطبق الجودة & & \\
\hline 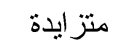 & 0,5722 & 0,4278 & 0,6239 & 0,3761 & يطبق الجودة & \multirow{2}{*}{ البقدونس } & \multirow{2}{*}{0} \\
\hline ثابتة & 0,0000 & 1,0000 & 0,0000 & 1,0000 & لا يطبق الجودة & & \\
\hline
\end{tabular}

XLDEA المصدر : اعتمد على مخرجات برنامج لإندة

Fayoum J. Agric. Res. \& Dev., Vol. 33, No.1, January, 2019 
119

التكاليف الأخري تشير إلي (تكاليف الأجولة، الكرتون، المواد اللاصقة، أكياس البولي أثثلين، الخيط،

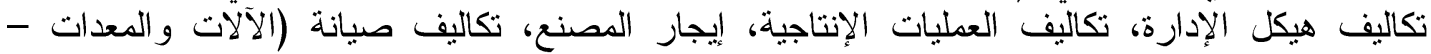

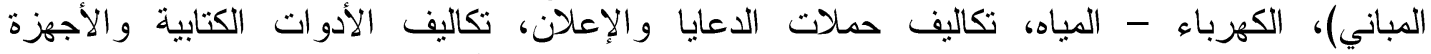

$$
\text { الكركدية: المستخة، تكاليف الجودة "المشرروعات التي تطبق نظام إدارة الجودة"). }
$$

تشير بيانات الجدول رقم (10) إلي أن غلة الحجم لمنتج الكركدية ثابتة في المشروعات التي لا تطبق

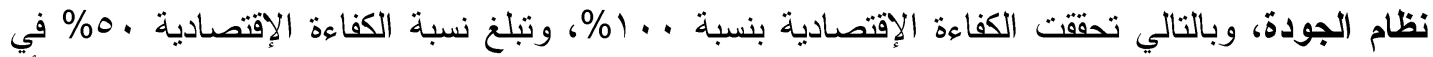

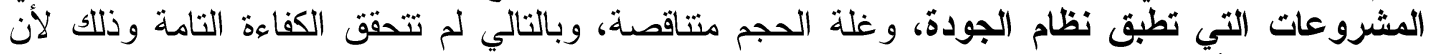

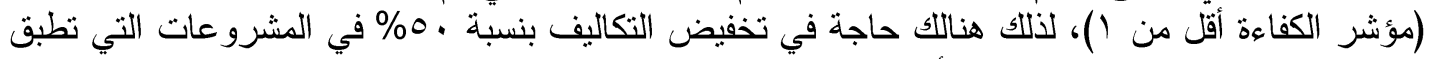

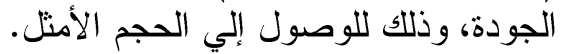
(البقدونس:

تشير بيانات الجدول رقم (10) إلي تقدير الكفاءة الإقتصادية في حالة ثبات العائد للسعة للتكاليف

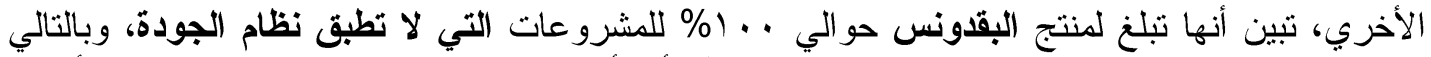

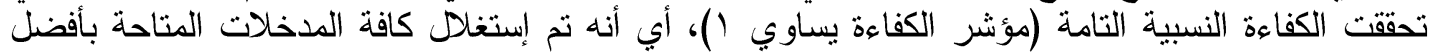

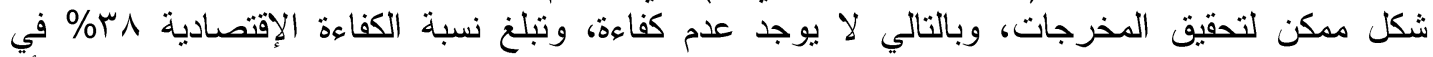

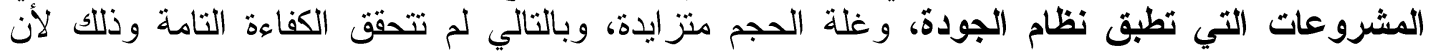

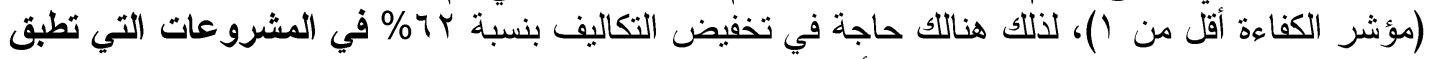

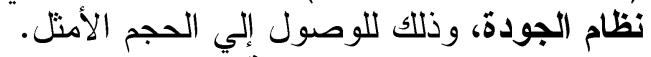
ب- العائد المتغير علي السعة:

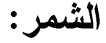

تشير بيانات الجدول رقم (10) إلي تقدير الكفاءة الإقتصادية في حالة تغير العائد للسعة للتكاليف

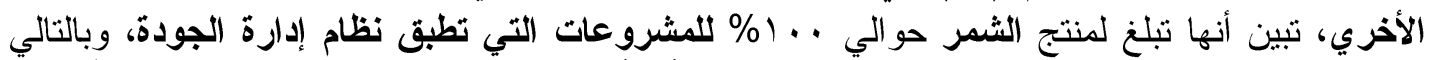

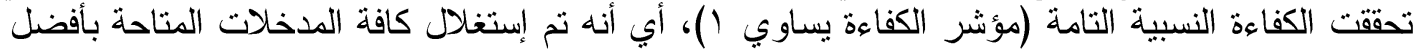

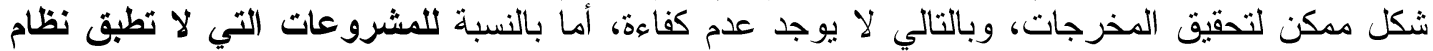

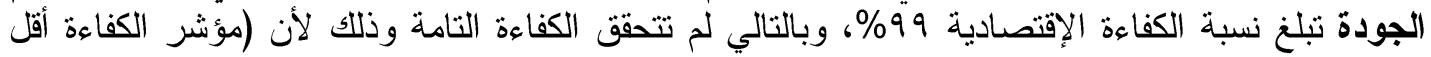

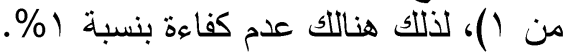
النعناع:

تشير بيانات الجدول رقم (10) أن الكفاءة الإقتصادية لمنتج النعناع في المشروعات التي تطبق والتي

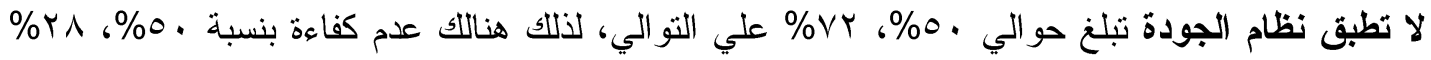

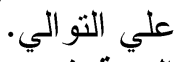
البردقوش: البوال

يتضح من بيانات الجدول رقم (10) أن الكفاءة الإقتصادية لمنتج البردقوش في المشروعات التي

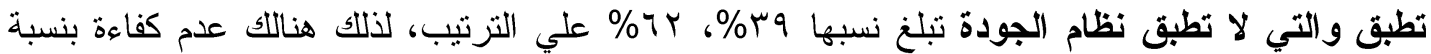
\% \% \% \% \%

Fayoum J. Agric. Res. \& Dev., Vol. 33, No.1, January, 2019 
$1 \%$.

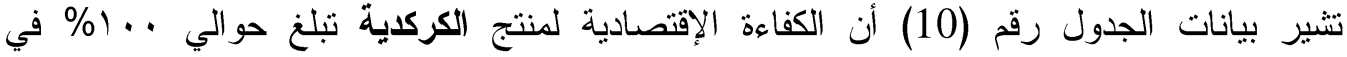
المشروعات التي تطبق والتي لا تطبق نظام الجودة، وبالتالي تحققت الكفاءة النسبية التامة (مؤشر الكفاءة التهاءة

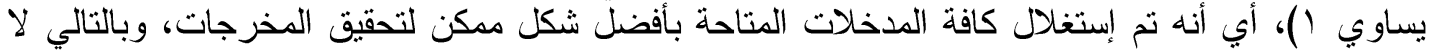
يوجد عدم كفاءة. البقدونس:

يتضح من بيانات الجدول رقم (10) أن الكفاءة الإقتصادية لمنتج البقدونس تبلغ حوالي . . 1)

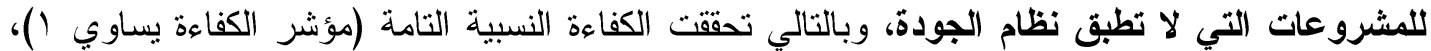

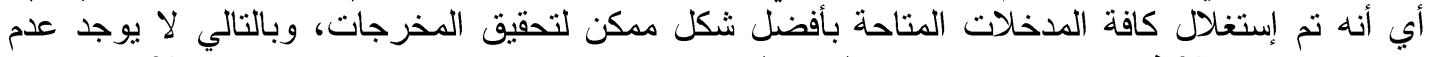

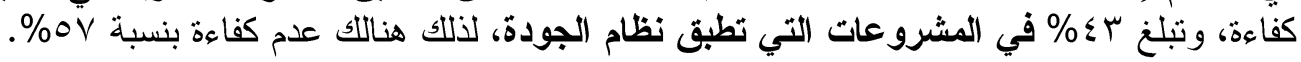
الملخص و التوصيات:

تستهدف الدراسة قياس أثز تطبيق إدارة الجودة الثاملة علي الكفاءة الإقتصادية لبعض مشروعات تجهيز وتجفيف الحاصلات الزراعية بمحافظتي الفيوم وبني سويف باستخدام أسلوب تحليل مغلف البيانات "Data Envelopment Analysis Program

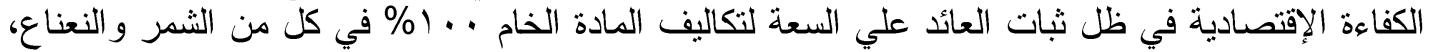

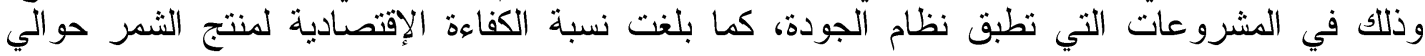
\%VV

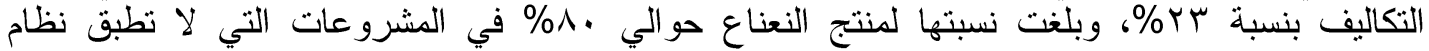

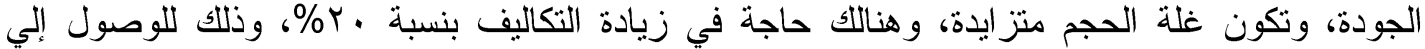

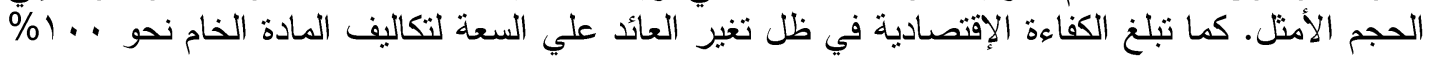

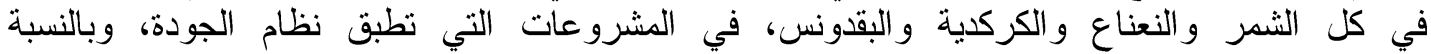

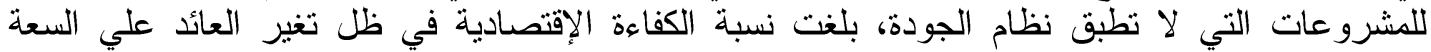

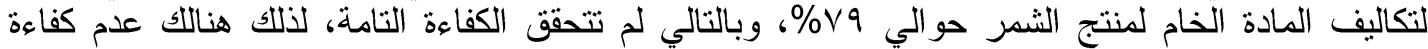

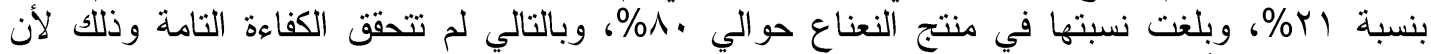

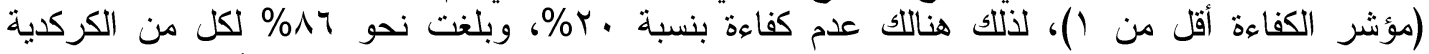

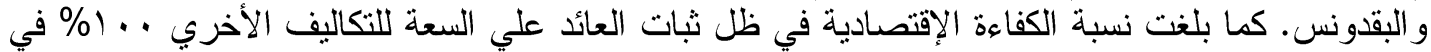
الثمر، وذللك في المشروعات التي تطبق نظام الجودة، كما بلغت نسبة الكفاءة الإقتصادية للمنتج الثمر

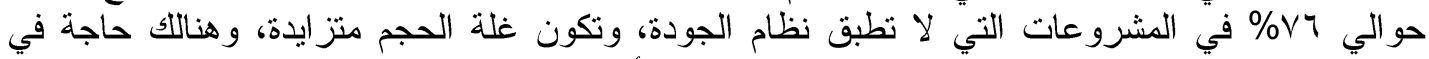

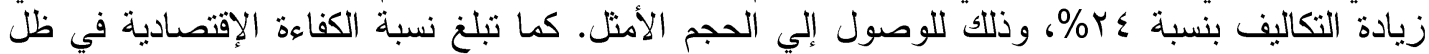

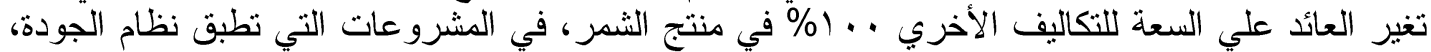

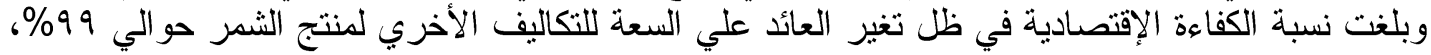

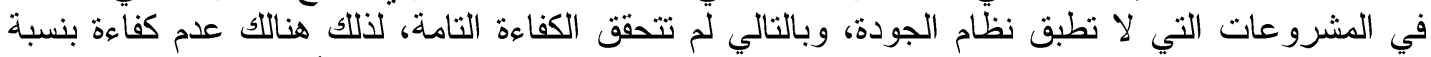

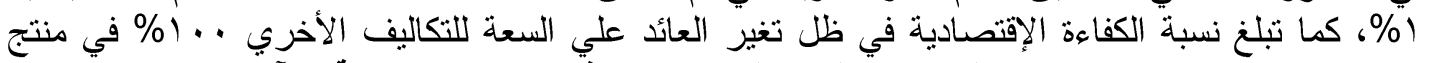
الكركدية، في المشروعات التي تطبق و لا تطبق نظام الجودة. لذلك توصي الار اسة بالآتي:

Fayoum J. Agric. Res. \& Dev., Vol. 33, No.1, January, 2019 
$|r|$

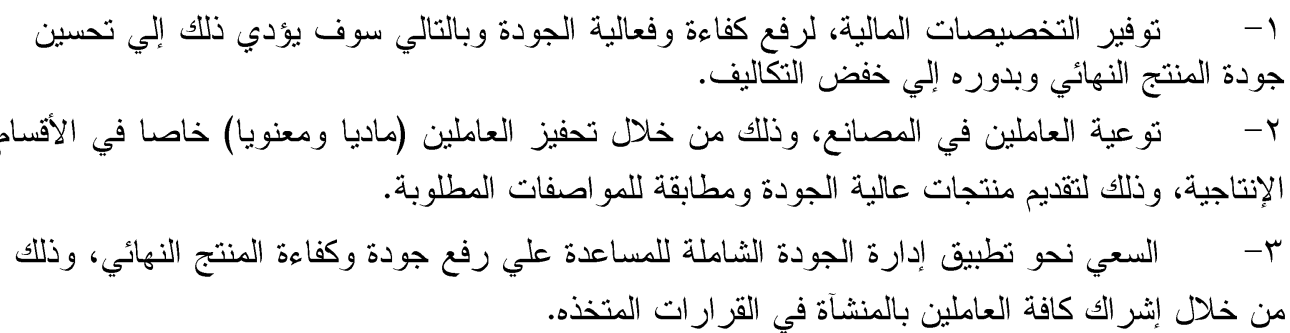

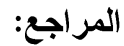

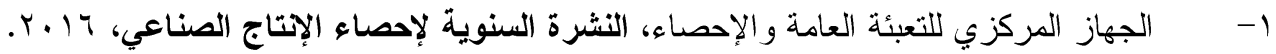

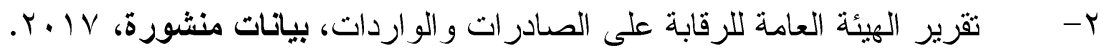

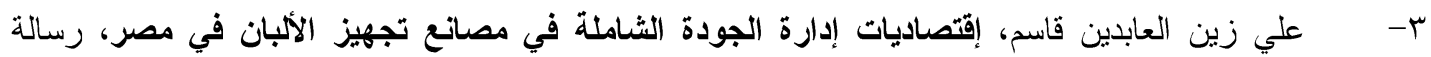

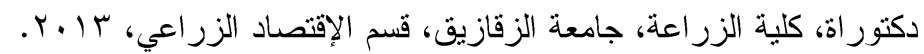

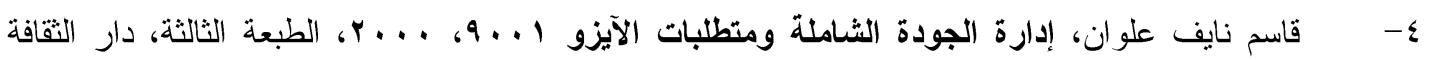

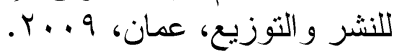

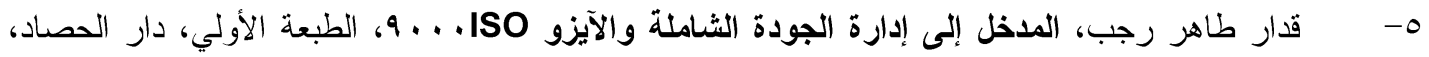

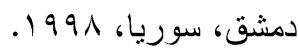

6- $\quad$ Cooper, W. W., Seaford, L., Tone, K. (2007). Data Envelopment Analysis, $2^{\text {end }}$ Ed. Springer Science + Business Media, USA.

7- Cooper, W. W., Seaford, L. and Tone, K. (2006). Introduction to Data Envelopment Analysis, ${ }^{\text {end }}$ Ed. Springer Science + Business Media, USA.

8- $\quad$ Kumar, M. R. (2004), Total Quality Management as the basis for organizational Transformation of Indian railways - A study in action research. Doctorate thesis, Business administration, Southern Cross University (India).

\title{
MEASURING THE IMPACT OF THE APPLICATION OF TOTAL QUALITY MANAGEMENTS ON THE ECONOMIC EFFICIENCY OF SOME PROJECTS OF PROCESSING AND DRYING AGRICULTURAL CROPS
}

Prof. Dr. Enas El-Sayed Sadek Prof. Dr. Mohamed Ahmed Said Eng. Marwa Badawi Sayed

\begin{abstract}
The study aimed to measure the impact of the application of Total Quality Management (TQM) on the economic efficiency of some projects of processing and drying agricultural crops in Fayoum and Beni-Suef governorates using Data Envelopment Analysis Program. The study reached some of the most important results: The rate of economic efficiency in the model of change in return on capacity for the cost of raw material $100 \%$ in both fennel and mint. The projects that implement the quality system and the economic
\end{abstract}

Fayoum J. Agric. Res. \& Dev., Vol. 33, No.1, January, 2019 
efficiency of the fennel product are about $77 \%$ in projects that do not apply the quality system. The yield is increasing, there is a need to increase costs by $23 \%$. The percentage of mint production is about $80 \%$ in projects that do not apply the quality system. The yield is increasing, there is a need to increase costs by $20 \%$, in order to reach the optimal size. As well as the economic efficiency in the model of change in return on a capacity for the cost of raw material is $100 \%$ in all fennels, mint, hibiscus and parsley. The projects implement the quality system. The projects that do not apply the quality system, the rate of economic efficiency in the model of change in return on capacity for the cost of the raw material of the fennel product is about $79 \%$. Consequently, full efficiency was not achieved. Therefore, there is inefficiency of $21 \%$, and its percentage in the product of mint about $80 \%$. Thus, full efficiency is not achieved because (the efficiency index is less than 1). So there is an inefficiency of $20 \%$. The rate of economic efficiency in the stability of return on capacity for other costs $100 \%$ in the fennel, the projects that applied the quality system. The economic efficiency of the fennel product is about $76 \%$ in projects that do not apply the quality system. The yield is increasing, there is a need to increase costs by $24 \%$, in order to reach the optimal size. The economic efficiency in the model of change in return on a capacity for the other cost is $100 \%$ in the fennels. The projects that are applied the quality system. The rate of economic efficiency in the model of change in return on capacity for the other costs of the fennel product is represented 99\%. The projects that do not apply the quality system, consequently, full efficiency were not achieved. Therefore, there is inefficiency of $1 \%$. The economic efficiency in the model of change in return on capacity for the other costs is $100 \%$ in the product of the hibiscus, in the projects that apply and do not apply the quality system.

\section{Therefore, the study recommends the following:}

1- $\quad$ Providing financial allocations, to raise the efficiency and effectiveness of quality. Thus, it will improve the quality of the final product and in turn to reduce costs.

2- $\quad$ Raising awareness of workers in the factories, by motivating the workers (material and moral) especially in the production departments, in order to provide products of high quality and conform to the required specifications.

3- $\quad$ To strive for the enforcement of TQM to help raise the quality and efficiency of the final product by involving all stakeholders in the decisions taken.

Fayoum J. Agric. Res. \& Dev., Vol. 33, No.1, January, 2019 